\title{
Enriched Environment Priors to TET1 Hippocampal Administration for Regulating Cognitive and Psychiatric Behaviors via Glial Reactivity in Chronic Cerebral Hypoperfusion Models
}

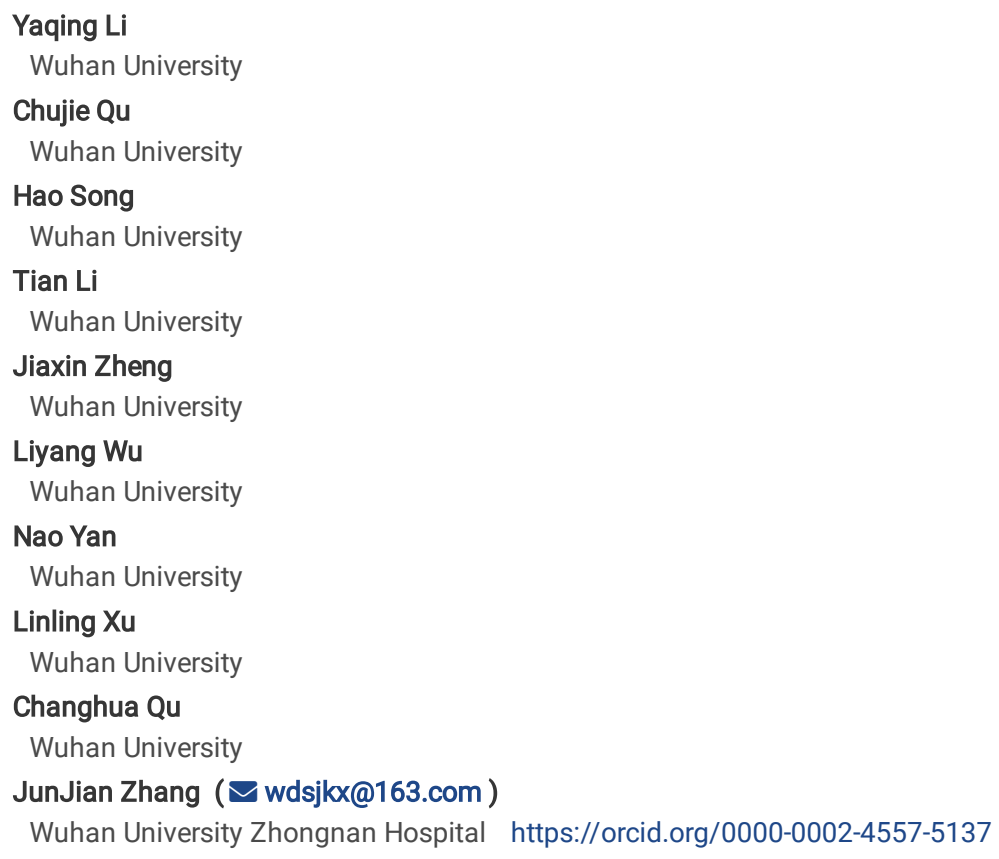

Research Article

Keywords: Adult hippocampal neurogenesis, TET1, Enriched environment, Glial reactivity, Cognitive dysfunction, Depression

Posted Date: July 20th, 2021

DOl: https://doi.org/10.21203/rs.3.rs-721526/v1

License: (1) This work is licensed under a Creative Commons Attribution 4.0 International License. Read Full License

Version of Record: A version of this preprint was published at Journal of Affective Disorders on April 1st, 2022. See the published version at https://doi.org/10.1016/j.jad.2022.04.087. 


\section{Abstract}

Increased understanding of chronic cerebral hypoperfusion $(\mathrm{CCH})$ has gradually been conscious of consisting a common etiologic mechanism for cognitive and psychiatric disturbances, and remains a matter to acquire a potential new therapeutic avenue benefiting from it. In the present study, we found genetical treatment with overexpressing a catalytic domain of human TET1 (AAV-hTET1) or enriched environment (EE) was sufficient for stimulating adult hippocampal neurogenesis (AHN). However, promoting ANH could not deal with the cognitive dysfunction and depressive-like behaviors in CCH rats. Notably, healthy local brain environment with elevated BDNF and less astroglia reaction was conducive to improve cognitive dysfunction. Meanwhile, astrocytes were involved in the regulating process of neurons, presynaptic function and microglia in the cognition. In addition, depressive disturbances were determined by glial activation containing astrocytes and microglia, BDNF levels, as well as neuronal and presynaptic function. To support this, we investigated astroglia and microglia activation was strongly correlated with severe depressive symptoms. Importantly, causal mediation analysis showed significant mediation by presence of reactive glial cells in the relation between neural plasticity and depressive symptoms. Finally, we compared the efficiency of genetical therapy and EE to treat cognitive dysfunction and depressive-related disorders in $\mathrm{CCH}$ rats. We showed EE performed better than hTET1 treatment for cognitive deficits and depression, and glial activation was important for the discrepancy for cognition, with glial reactivity and presynaptic function devoting to the different efficiency for depression. These results were important for our understanding of disease mechanisms and provided valuable tools for the overall management of $\mathrm{CCH}$ patients.

\section{Introduction}

Dementia, an acquired loss of cognition in multiple cognitive domains, is a common public health problem [1]. Although the heterogeneity of clinical presentation of dementia subtype, cerebrovascular dysfunction at some point shared to be one common etiology among all dementia subtypes [2]. Additionally, depression has been widely co-occurred with cognitive impairment, and constitutes an important mental part of dementia [3]. Similar with dementia, the depression was also highly related to vascular pathophysiology [4], which called vascular depression hypothesis. Chronic cerebral hypoperfusion has been verified to be an early pathological event during alzheimer's disease (AD) development [5]. Also, chronic hypoperfusion also induces a depressive-like behaviors and reduces the sensitivity of cortex to cortical spreading depression elicitation [6,7]. However, the explicit mechanism underlying vascular-related cognition impairment and depression is still unclear to some extent, which inevitably delays the progression of disease-modifying drug.

By virtue of unique structure and functional plasticity in the dentate gyrus (DG), the hippocampus plays a crucial role in learning and memory formation, as well as regulation of mood [3]. Adult neural stem cells (NSCs) undergo self-renewal by mitotic cell division and sequentially differentiate into neuroblasts and finally generate new neurons [8], the process called adult hippocampal neurogenesis (AHN). Both animal experiments and human clinical research have reported altered $A H N$ in $A D$ and depression [9-11]. In addition, promoting AHN can ameliorate AD pathology and cognitive impairment under a healthier, improved local brain environment [9]. To data, the evidence that whether the altered AHN can explain the mechanism underline the co-occurrence of cognitive deficits and depression related to vascular pathophysiology has remained sparse and inconclusive. Besides, whether AHN could be improved and exploited for the therapeutic target for vascular-related dementia also needed to be explicated.

Another potential candidate for effecting vascular-related co-occurrence of cognitive deficits and depressive-disorders might be the glial activation. As reported, microglia and astroglia were normally susceptible to various neuropathological stimuli. Once activated, usually followed by release of neurotoxic factors and neuronal deficits, participating in pathogenesis of CNS disease[12]. Several groups have shown that alteration of reactive astrocytes and microglia were observed in $A D$ rodents and post-mortem tissue of $A D$ patients [13-16]. In addition, depression also was correlated with glial activation in vivo and clinical researches $[17,18]$. However, the effect of glial reaction on vascular-associated cognitive impairments and depression was not as well understood.

Therefore, we generated a model of chronic cerebral hypoperfusion through bilateral occlusion of common carotid artery (2-V0) surgery to examine the cognitive and depressive behaviors. Recent researches have displayed that both ten-eleven translocation methylcytosine dioxygenase 1 (TET1) and enriched environment (EE) were enough for stimulating AHN [19-21]. Meanwhile, the existence of EE has been identified to trigger benefits for the astrocytes and microglia [22,23], thus reducing neuroinflammation and devoting protection to CNS insults [24,25]. However, less evidence to investigate the mechanisms underlie TET1 and glial reactivity. Taken these into account, we compared novel genetical treatment with hTET1 hippocampal microinjection and regular enriched environment to observe which one is more suitable for the cognitive and depressive disturbance and to investigate the underlying mechanism of its treatment for therapy of cognition and depression in $\mathrm{CCH}$ models from standpoint of AHN and glial activation.

\section{Methods}

\section{Animals and experiment design}

Experimental procedures were approved by the Animal Ethics Committee of the Medical School of Wuhan University (Protocol 2018046) following the protocols of National Institutes of Health Guide for the Care and Use of Laboratory Animals. All adult male Sprague-Dawley rats (220-240g) were purchased from Vital River Laboratory Animal Technology Co. Ltd., Beijing, China. Rats were group-housed in a pathogen-free environment with constant temperature (22 $\pm 2 \circ \mathrm{C})$ on a $12 \mathrm{~h}$ day/night cycle, relative humidity of $55 \pm 5 \%$, and provided with unlimited food and water.

All rats were subjected to stereotaxic injection of phosphate-buffered saline (PBS) or AAV-hTET1. The 2 VO and sham surgery was carried out 10 days later. The total mortality rate after stereotactic injection and 2-VO surgery was approximate $20 \%$. After 3 days recovery, rats were subjected to standard environment or enriched environment with free access to food and water. 3-4 rats in each group underwent 5-bromo-2-deoxyuridine (BrdU) injection (200 mg/kg, i.p. once daily) per day for five consecutive days from 12th and 34th after 2-VO or sham surgery, respectively. 3-4 rats in each group were injected with BrdU once for 3 days, and rats were sacrificed $4 \mathrm{~h}$ after the last injection. The behavior tests containing sucrose preference test (SPT), open field test (OFT), novel object 
recognition test (NOR), and Morris water maze (MWM) were performed in turn before sacrifice. All rats were sacrificed on the 47nd day after 2-VO or sham surgery. A summary of experiment design was presented in Fig. 1.

\section{Stereotaxic microinjection of adeno-associated virus vectors}

Rats were anesthetized with $1 \%$ Pelltobarbitalum Natricum (40 mg/kg, i.p.) and placed in a stereotaxic frame. Equal numbers of rats were injected with either PBS or AAV9 vector containing GFP and catalytic domain of human TET1 genes (NM_030625 1418-2136aa) in bilaterally DG of the hippocampi (3 $\mu$ l per side of $1 \times 10^{12}$ viral genome particles $/ \mathrm{ml}$ ) at the following coordinates with an injection rate of $0.5 \mu \mathrm{L} / \mathrm{min}$ : anteroposterior $=3.8 \mathrm{~mm}, \mathrm{mediolateral}= \pm 2.3 \mathrm{~mm}$ and dorsoventral from the bregma $=-3.5 \mathrm{~mm}$. In order to prevent reflux and allow solution diffusion, the needle was maintained still for $5 \mathrm{~min}$ and then withdrawn very slowly after microinjection.

\section{Chronic cerebral hypoperfusion surgery}

Rats were anesthetized with $1 \%$ Pelltobarbitalum Natricum (40 mg/kg, i.p.) to perform bilateral common carotid artery occlusion (2-vessel occlusion, 2V0) [26]. Briefly, a ventral incision was made in the midline of the neck, and the bilateral common carotid arteries were carefully exposed with carefully separating from the arterial sheath to avoid damage to the vagal nerves. Animals in the $2 \mathrm{VO}$ group had both left and right common carotid arteries permanently occluded via doubly ligated with 4-0 silk suture, and the time interval of surgery between two side was 30 minutes. Sham group performed the same surgical procedures without ligation of the common carotid arteries. The rectal temperature was maintained between $36.5^{\circ} \mathrm{C}$ and $37.5^{\circ} \mathrm{C}$ until rats recovered from anesthesia.

\section{Environmental enrichment}

Animals were exposed to enriched environment in a large cage $(95 \times 75 \times 45 \mathrm{~cm})$ made of wire mesh and glass wall at a fixed time between 8 a.m. and 4 p.m. every day for 1 month. The enriched environment cage equipped with many objects, such as running wheels, toys, tunnels of various shapes or platforms made of plastic, metal or wood. Objects were altered with a new set three times a week and cleaned up with $75 \%$ ethanol once week. Food and water were easily available during the period of environmental enrichment. Rats in standard and enriched environment conditions were housed in the same room.

\section{Behavioral tests}

\section{Open field test (OFT)}

The apparatus was a wooden box without top structure (100 cm length, $100 \mathrm{~cm}$ width, $40 \mathrm{~cm}$ height). The bottom of apparatus was equally divided into 25 squares by virtual lines. All rats were individually placed in the center area allowing to explore freely for 5 min with a recording by a digital camera above the box. The OFT indicators, including crossing numbers, rearing numbers and grooming times were recorded manually by the investigator. The apparatus was cleaned with $75 \%$ ethanol after each rat.

\section{Sucrose preference test (SPT)}

Rats were easily available to two drinking bottles for $24 \mathrm{~h}$, one with $1 \%$ sucrose solution $(\mathrm{w} / \mathrm{v})$ and the latter with water only. The positions of bottles were changed every $12 \mathrm{~h}$ to avoid position preferences. Before testing, the rats were deprived of water for $24 \mathrm{~h}$. Every rat was put in the individual cage $1 \mathrm{~h}$ with accessing to two drink bottles freely, one containing $100 \mathrm{ml} 1 \%$ sucrose solution and the other containing $100 \mathrm{ml}$ water. The sucrose preference ratio was calculated as follows: Consumption volume of sucrose solution/(Consumption volume of sucrose solution+ Consumption volume of water) $\times 100 \%$.

\section{Novel object recognition test (NOR)}

The novel-object recognition test was conducted in a white open box ( $60 \mathrm{~cm}$ length, $60 \mathrm{~cm}$ width, $40 \mathrm{~cm}$ height). Rats were individually placed in the center of the open field and was allowed to explore the area for $5 \mathrm{~min}$ without object. On the first day, rats were familiar with two identical objects for $15 \mathrm{~min}$ freely. On the second day at the same time, the rats were subjected to the recognition box with one old object and a newly introduced novel object for 5 min, and the time of object exploration was recorded when the rat explored the object with directing its nose at an object within $1 \mathrm{~cm}$ or less by investigator who was blinded to the grouping. Novel object recognition ratio was calculated as following formula: time of novel object / (time of novel object + time of familiar object). The inside of the reaction box was cleaned up with $75 \%$ ethanol after each trail.

Morris water maze (MWM)

The Morris water maze test was subjected to assess spatial learning and memory. The MWM equipment is a circular pool $(150 \mathrm{~cm}$ in diameter $50 \mathrm{~cm}$ in height) filled with non-toxic dyed dark water to a depth of $32 \mathrm{~cm}$, maintained at $24 \pm 1 \circ \mathrm{C}$. Several orientation cues were placed on the wall around the pool. The pool was evenly divided into 4 quadrants, with the black platform $(10 \mathrm{~cm}$ in diameter and $30 \mathrm{~cm}$ in height) was submerged in the center of first quadrant. The space navigation training stage will process on five consecutive days with 4 trail every day, rat was randomly placed into the pool from four different quadrant in each trail, with its back on the wall of pool. In each trial, the rat was allowed to search the platform for at maximum of 60 s and stay for $15 \mathrm{~s}$. If the rat failed to find the platform within $1 \mathrm{~min}$, the investigator needs to guide it to find the platform. The parameter of the latency time (at maximum of $60 \mathrm{~s}$ ) was recorded by the experimenters using the Animal Video Tracking Analysis System (AVTAS ver 4.0, Anilab Scientific Instruments Co., Ltd., Ningbo, China). During the exploration task stage at the sixth day, the platform was removed from the first quadrant, the rat was placed from the third quadrant and the rat was changeling to swim for $60 \mathrm{~s}$. The time of the rats swimming in the target quadrant was measured. The rats were gently dried and gently return to their cage after trail. 
The total RNA isolated from rat hippocampus was stored with a chemical kit (Aidlab, Beijing, China) following the manufacturer's instructions in -80 ${ }^{\circ} \mathrm{C}$. $c D N A$ was obtained by reverse transcription with mRNA in a 20-ul solution in accordance with a ReverTra Ace qPCR RT Kit (Toyobo, Japan). Real-time PCR was processed in the CFX96 RT-qPCR Detection System (Bio-Rad, USA) and applied SYBR Premix ExTaq (Takara, Japan). Primers were designed and synthesized by HYcell biotechnology company (Wuhan, China). The sequences of primers for RT-PCR are listed in Table S1. Quantification of cDNA was controlled by normalization of $\beta$-actin. The relative abundance of mRNA expression was calculated by the $\triangle \triangle \mathrm{Ct}$ method.

\section{Western blotting}

The total protein of rat hippocampus was extracted using RIPA lysis buffer (P0013B; Beyotime Biotechnology) containing PMSF (ST505; Beyotime Biotechnology) and cocktail (P1010; Beyotime Biotechnology), centrifuged (12,000 g, $10 \mathrm{~min}, 4 \circ \mathrm{C})$ for collecting supernatants, and stored in $-80^{\circ} \mathrm{C}$. The protein concentrations were determined using the BCA kits (P0010; Beyotime Biotechnology). In total, $30-50 \mu$ g of protein was separated by SDS-PAGE, transferred onto polyvinylidene fluoride membrane, blocked with TBST containing $5 \%$ skim milk power, and incubated overnight at $4{ }^{\circ} \mathrm{C}$ with diluted primary antibodies. The antibodies were shown in Table S2. Horseradish peroxidase-conjugated secondary antibody was applied to incubate the membranes at room temperature for $2 \mathrm{~h}$. Visualization and semi-quantitation of target protein expression were observed by an enhanced chemiluminescence system (Tanon-5200, Shanghai, China) and calculated by ImageJ software (NIH, USA).

\section{Microglial activation, astrocytes and neuronal proliferation based on immunofluorescence}

Rats were anesthetized with $1 \%$ Pelltobarbitalum Natricum (40 mg/ $\mathrm{kg}$, i.p.) and perfused transcardially with $0.9 \%$ saline and followed by $4 \%$ paraformaldehyde in $0.1 \mathrm{M}$ phosphate-buffered saline. Brains were rapidly dissected, post-fixed with $4 \%$ paraformaldehyde for $24 \mathrm{~h}$, embedded, and cut into sections containing the hippocampal DG area. The slices were washed three times for 7 min in PBS, blocked with $10 \%$ normal goat serum (NGS) and incubated with primary antibodies overnight at $4^{\circ} \mathrm{C}$. The antibodies were shown in Table S2. Subsequently, sections were next incubated with fluorescent Cy3 labeled goat anti-mouse antibody (1:300) or Cy3 labeled goat anti-rabbit antibody (1:300) for 1h at room temperature in the dark. DAPI (sc-3598; Santa Cruz) for $5 \mathrm{~min}$ was applied to visualize the nuclei after the secondary antibody was washed off. This technology is supported by Baiqiandu Technology Company (Wuhan, China). All slices were observed under an Olympus BX53 microscope at 400x magnification with identical imaging parameters and software settings. Cell number quantification was done by the blinded experimenter. The total number of microglial cells, astrocytes and neuronal proliferation in per unit volume of dentate gyrus was calculated by blinded experimenter using ImageJ software (NIH, USA).

\section{Statistical Analysis}

Statistical analysis was performed using GraphPad PRISM 7 software (GraphPad Software, USA). Data were expressed as mean \pm standard error of the mean. Un-paired t test was used to analyze observation results between two independent groups of rats. ANOVA followed by post hoc Bonferroni test was applied for comparisons among multiple groups. We performed one-way variance (ANOVA) tests followed by post-hoc Bonferroni test to assess the significance comparisons among multiple groups expect for escape latency, which was analyzed by a two-way repeated-measures ANOVA followed Fisher's least significant difference test. Association analysis was performed using model adjusted by group. Mediation analysis was performed in R using "mediation" package. P-values $<0.05$ were defined statistically significant.

\section{Results}

\section{Contribution of AAV-hTET1 or environmental enrichment to depressive-like behaviors in $\mathrm{CCH}$ rats}

The depressive-like behaviors were evaluated by SPT and OFT tests (Fig.2 and Fig.S1).

Under normal circumstance, AAV-hTET1 group exhibited lower sucrose preference (Fig.S1 a). Similarly, the difference of the sucrose preference in 2VO+AAVhTET1 or 2VO+AAV-hTET1+EE group reached the statistically significant when in comparation with $2 \mathrm{VO}$ rats (Fig.2 a). No matter whether exposed to enriched environment or not, comparable consumption ratio of sucrose solution was displayed in rats subjected to $\mathrm{CCH}$ and corresponding sham controls (Fig.2 a).

Compared to sham group, EE could increase the crossing and rearing numbers in exploratory behaviors (Fig.S1 i,k), and 2VO rats exhibited an increased exploratory and locomotor activity, which was indicated by more numbers of rearing and line crossing (Fig.2 d,b). However, AAV-hTET1 intervention attenuated the efficiently of increased exploratory and locomotor activity induced by $2 \mathrm{VO}$ by reduction in crossing numbers, grooming times, as well as rearing numbers (Fig.2 b-d). There was no significant difference in 2VO group, 2VO+EE group and 2VO+AAV-hTET1+EE group (Fig.2 b-d).

\section{Effects of AAV-hTET1 or environmental enrichment on mild cognitive impairment in CCH rats}

Figure displayed the results of NOR and MWM test (Fig.2 and Fig.S1).

The NOR test was applied to assess hippocampus-dependent recognition memory in the rodents. No differences in novel object recognition ratio were found after 2VO treatment, AAV-hTET1 microinjection or environmental enrichment (Fig.2 e).

The MWM test was subjected to assess spatial learning and memory. Collectively, AAV-hTET1 group demonstrated shorter time to find the hidden platform on day 2, 3 and 4, while the EE group performed much better and spend less time for 5 consecutive days, when compared to corresponding sham group (Fig.S1 f, m). There was no doubt that both the AAV-hTET1 group and EE group stayed more time in targeted quadrant on day 6 (Fig.S1 g, n). Then, we identified whether the improved capability of AAV-hTET1 injection or enriched environment in spatial learning and memory was capable for the CCH rats. On day 1 , rats 
in the 2VO group took longer time to stand on the hidden flatform than sham rats, and this situation was sustained for next 4 consecutive days (Fig. $2 \mathrm{f}$ ). Similarly, the EE intervention or combined treatment of EE and AAV-hTET1 greatly diminished the time spent to detect the flatform caused by $2 \mathrm{VO}$ surgery for 5 days (Fig. $2 \mathrm{f}$ ). In addition, the longer time to detect the hidden flatform in 2VO rats was also reversed by AAV-hTET1 microinjection on day 1, 4 and 5 (Fig. $2 \mathrm{f}$ ). Notably, the capacity of improved memory deficits of EE intervention was more likely obvious than AAV-hTET1 targeted microinjection in hippocampus, as the $\mathrm{CCH}$ rats after EE intervention could find the hidden flatform faster than that after AAV-hTET1 on day 2 and 4 (Fig. $2 \mathrm{f}$ ). The hidden platform was removed on day 6 to carry out the probe trial test. While the time spent in the target quadrant in $2 \mathrm{VO}$ rat was equally with the time spent in sham rats, treatment of AAVhTET1, EE or AAV-hTET1 $\times$ EE interaction could greatly prolong the time spent in the target quadrant compared to corresponding $2 \mathrm{VO}$ rats (Fig. $2 \mathrm{~g}$ ).

\section{AHN stimulation with AAV-hTET1 or with environmental enrichment in $\mathrm{CCH}$ rats}

To investigate the NPC proliferation of hippocampal function, we performed AAV-hTET1 injection and enriched environment. Before that, we found that TET1 mRNA expression was marginally lower in $\mathrm{CCH}$ rats than that in sham rats and EE could not change the TET1 expression (Fig.S2 a). AAV-mediated expression was observed in DG of the hippocampus and expression of hTET1 across 5 groups has been shown in Fig.S2 b-c. Successful proliferation of NSCs with AAVhTET1 or with enriched environment alone was determined by significantly higher number of BrdU ${ }^{+}$cells in the SGZ compared with sham group (Fig.S3 a-b). In order to detect whether the application of hTET1 or EE could improve the proliferation of hippocampal DG in CCH rats, we found that an approximate 1.75 folds versus 2.11 folds in the quantitation of proliferating NSCs in the therapy of hTET1 overexpression and EE, respectively, relative to 2 VO group (Fig. 3 a). Interestingly, the combination of AAV-hTET1 and enriched environment seemed not to increase more proliferative capacity of NSCs compared to single therapy alone, as assessed by similar amount of BrdU ${ }^{+}$cells in 2VO + AAV-hTET1, 2VO + EE and 2VO + AAV-hTET1 + EE group (Fig.3 a).

We next assessed the differentiation of NSCs by examining BrdU incorporation in immunostaining for $\mathrm{DCX}^{+}$neurons. Compared to sham group, the BrdU ${ }^{+}$ neuronal precursor cells expressed significant in EE group, and both EE group and hTET1 overexpression significantly increased the DCX positive immature neurons and $\mathrm{DCX}^{+} \mathrm{BrdU}^{+}$newborn neurons (Fig.S3 c-d), demonstrating that the BrdU neuroblasts might be increased as the total number of neuroblasts increased. Besides, the cell counting of $\mathrm{BrdU}^{+}, \mathrm{DCX}^{+}$and $\mathrm{BrdU}^{+} / \mathrm{DCX}^{+}$cells did not get significance in in $2 \mathrm{VO}$ group compared to sham controls (Fig. $3 \mathrm{~b}$ ). Furthermore, we identified that the numbers of $\mathrm{BrdU}^{+}, \mathrm{BrdU}^{+} / \mathrm{DCX}^{+}$and $\mathrm{DCX}^{+}$cells were obviously higher after EE treatment than $2 \mathrm{VO}$ surgery, so did similarly after the the AAV-hTET1 microinjection alone or combined treatment including AAV-hTET1 and EE, but with one exception of the BrdU ${ }^{+}$neuronal precursor cells in AAV-hTET1 group (Fig.3 b).

Finally, we tested whether adult neurogenesis could trigger a persistent increase in the survive and mature during the generation of newborn mature neurons induced by hTET1 overexpression or EE. Unfortunately, the expanded cohort of NSCs differentiation did not lead to apparently increased numbers of BrdU ${ }^{+}$ cells, $\mathrm{BrdU}^{+} / \mathrm{NeuN}^{+}$newborn mature neurons, and $\mathrm{NeuN}^{+}$mature neurons during hTET1 administration relative to controls, on the contrary, a downward trend in $\mathrm{BrdU}^{+}$cells and $\mathrm{BrdU}^{+} / \mathrm{NeuN}^{+}$newborn mature neurons (Fig.S3 e). Irrespective of comparable populations of BrdU-positive cells and approximate 4-weekold neurons $\left(\mathrm{BrdU}^{+} / \mathrm{NeuN}^{+}\right)$, EE group exhibited increase in the total number of $\mathrm{NeuN}^{+}$mature neurons compared with sham controls (Fig.S3 $\mathrm{f}$ ). For the sake of evaluating the effect of neurogenesis survival and mature after EE or hTET1 microinjection in CCH rats, our results showed more NeuN-positive mature neurons with little influence on the amounts of BrdU- and BrdU/NeuN- positive cells in environmental enrichment rats, while the comparable numbers of NeuNpositive mature neurons accompanied with relative less BrdU- and BrdU/NeuN-positive cells were observed in hTET1 overexpression group, compared to $2 \mathrm{VO}$ rats (Fig. $3 \mathrm{c}$ ). The combined administration of targeted-hTET1 microinjection and environmental enrichment seemed to put a neutralizing outcome on neurogenesis survival and mature in comparation with hTET1 overexpression or environmental enrichment alone after 2VO surgery (Fig. $3 \mathrm{c}$ ).

\section{Hippocampal adult neurogenesis markers change after AAV-hTET1 or environmental enrichment in CCH rats}

Relative to sham controls, both AAV-hTET1 local administration and enhanced environment showed higher mRNA and protein levels of PCNA and DCX (Fig.S4 a-d), but the expression of NeuN could be used as a marker to distinguish AAV-hTET1 injection and enriched environment with lower NeuN mRNA in AAVhTET1 group and higher NeuN mRNA and protein in enriched environment group (Fig.S4 e-f). In line with the immunofluorescence results of hippocampal proliferation and differentiation, an obvious elevation of PCNA and DCX gene expression and protein concentration in hippocampus in 2VO+AAV-hTET1 group, 2VO+EE group, and 2VO+AAV-hTET1+EE group, respectively, as relative to $2 \mathrm{VO}$ group (Fig.4 a-b). Treatment with environmental enrichment could result in a significant increase of NeuN protein level in hippocampus by $24.2 \%$ compared with 2 VO group. Reversely, the effect of AAV-hTET1 microinjection did not get any improvement, but a trend towards to diminish the NeuN protein (Fig.4 c). Consistent with NeuN protein, the relative expression of NeuN mRNA was elevated in $2 \mathrm{VO}+\mathrm{EE}$ group compared to $2 \mathrm{VO}$ group (Fig. 4 c). Both the NeuN protein and gene expression in AAV $\times$ enriched environment combined therapy seemed to have a tendency to AAV microinjection alone (Fig.4 c).

\section{Microglia and astrocyte reactivity stimulation with AAV-hTET1 or with environmental enrichment in CCH rats}

In order to assess the microglia and astrocyte reactivity with AAV-hTET1 or with EE, we labeled the neurons with the microglia-specific marker IBA1 and astrocyte activation marker GFAP. The pattern of increase in the IBA $1^{+}$cells was evident in the microglia residing in DG after AAV-hTET1 treatment compared with control rats, but we did not identify activation of horizontal astrocytes assessing by GFAP staining (Fig.S5 a,c). In addition, less astrogliosis was induced with GFAP+ immunofluorescence with EE, although microglia activation was not sustained in the DG of rats relative to sham rats (Fig.S5 b,d). CCH rats could not produce increased activation of glial cells (Fig. 5 a-b). In comparation with 2 VO group, hTET1 overexpression presented high populations of IBA1- positive microglia and almost synchronously activated astrocytes in hippocampus (Fig. 5 a-b). Just opposite to hTET1 overexpression, EE administration showed obvious decreased numbers of IBA $1^{+}$microglia and GFAP ${ }^{+}$astrocytes (Fig. $5 \mathrm{a}-\mathrm{b}$ ). Relative to hTET1 or enhanced environment alone, the united therapy of these two markers tended to play an intermediate role in the reactivity stimulation of glial (Fig. 5 a-b).

Microglia and astrocyte markers variation in hippocampus

Page 5/20 
We also measured the gene expression and activation of astrocytes and microglia. Under sham situations, rats with AAV-hTET1 demonstrated higher GFAP and IBA1 expression in mRNA and protein concentration, and rats with enhanced environment upregulated the GFAP protein level (Fig.S5 e-h). Compared to 2 VO group, the expression of GFAP and IBA1 were accordantly upregulated after AAV-hTET1treatment, while enhanced environment downregulated the GFAP expression (Fig. 5 c-d), which suggested the activations of astrocytes and microglia were consistently promoted in 2VO+AAV-hTET1 group, and activation of astrocytes was inhibited in $2 \mathrm{VO}+\mathrm{EE}$ group.

\section{Alteration in brain-derived neurotrophic factor (BDNF) protein and mRNA expression in the hippocampus}

BDNF, released by astrocytes, microglia, and nerve terminals, is essential for adult hippocampal neurogenesis and memory formation. Hence, expression of BDNF expression was also explored in our study. Our results showed that BDNF expression was upregulated in the presence of AAV-hTET1 by $83.7 \%$ and $35.6 \%$ from qRT-PCR and immunoblots study when compared with sham group (Fig.S4 g). Compared to sham-operated rats, elevated levels of BDNF protein were detected in sham+EE rats (Fig.S4 h). Confront with sham controls, there were no difference of BDNF gene and protein expression in 2 VO rats, but a trend towards to reduction in 2VO rats (Fig.4 d). A significant elevation of BDNF expression was found by western blot after exposing to AAV-hTET1 microinjection, enriched environment or AAV $\times$ enriched environment interaction, as well as elevation of BDNF mRNA after AAV-hTET1 microinjection or interaction of AAV $\times$ enriched environment treatment (Fig.4 d).

\section{Alteration in presynaptic and postsynaptic protein and mRNA expression in the hippocampus}

In an attempt to assess whether synaptic function was participated in process of AAV-hTET1 or EE regulation, we investigated the PSD95 and SYP expressions in the hippocampus. Robust increases in gene expression and immunoblot reactivity of postsynaptic density 95 (PSD-95) was observed exposed to AAV-hTET1 or EE compared with sham rats (Fig.S4 i-j). Compared with sham controls, we observed a significant reduction in SYP protein after AAV-hTET1 treatment (Fig.S4 k-I). Compared with sham controls, CCH rats did not lead to any changes the SYP and PSD95 expression (Fig.4 e-f). Remarkably improved SYP mRNA, accompanied with a consistently marginal increase in SYP protein levels, was found in 2VO+EE group, but 2VO+AAV-hTET1 rats showed a significant reduction in SYP mRNA and protein expression in comparation with $2 \mathrm{VO}$ rats (Fig. $4 \mathrm{f}$ ). Encouragingly, the mRNA and protein expression of PSD95 were enhanced presented by qRT-PCR and western immunoblot results after intervention of AAV-hTET1 microinjection, enriched environment or AAV $\times$ enriched environment interaction (Fig. 4 e).

\section{Association analysis}

First, we assessed cognition associations with adult neurogenesis, synaptic functions, glial activation and BDNF levels, we found that spatial learning and memory were associated with an increase in BDNF and GFAP expression (Table 1). No markers were linked to recognitive memory in our results (Table 1). Second, we assessed depressive associations with adult neurogenesis, synaptic functions, glial activation and BDNF levels. Sucrose preference ratio was strongly linked to increased SYP expression and reduction in BDNF, IBA1 and GFAP expression. For open field test, crossing numbers and rearing numbers were negative related to GFAP and IBA1 expression, while grooming times was positive associated with NEUN expression (Table 2). Third, we investigated the correlation among adult neurogenesis, synaptic functions, glial activation and BDNF levels (Table 3). After controlling for group, SYP was apparently linked to a reduction in IBA1 and GFAP, and an increase in NEUN expression. GFAP was positively related to BDNF and IBA1, and negatively related to SYP and NEUN. Expect GFAP and SYP, IBA1 was also associated with decreased NEUN expression. In addition, PCNA was associated with DCX even controlled for group.

\section{Mediation analysis}

The mediation analysis outlined two main hypotheses (Fig.6-7 and Fig.S6-S9). First, the GFAP significantly mediated the relationship between the IBA1 and latency of WWM Day-5 (Fig.6 c). Similar GFAP mediated role was also observed in the SYP effect on latency of WWM Day-5 and NeuN effect on latency of WWM Day-5 (Fig.6 d,f). The interpretation was that astrocytes significantly mediated the effect of neuronal, pre-synaptic function and microglia on cognition function.

Second, for sucrose preference test, we observed SYP, GFAP and IBA1 were associated with alterations in positive effect of NeuN on sucrose preference (Fig.7 $a-b, d)$. Of note, there was a significant negative indirect effect of GFAP on sucrose preference through IBA1 (Fig.7 c). For open field test, indirectly positive correlation between NeuN and crossing numbers were significantly regulated by GFAP and IBA1 (Fig.7 h,k). IBA1 also mediated the effect of SYP on crossing numbers, and GFAP on crossing numbers (Fig.7 i-j). More increased NeuN levels were indirectly associated with more rearing numbers by GFAP (Fig.7 I). The potential hypothesis was that the effect of neuronal function on depression could regulated by presynaptic function. More importantly, astroglial and microglial activations were the important mediators, participant in the process of neuronal and presynaptic role in depression. Meanwhile, the microglial reactivity was involved in the correlation between astrocyte and depression.

\section{Discussion}

In individuals with $\mathrm{CCH}$, both EE and AAV-hTET1 local injection could improve the cognitive impairments, but our statistical results showed that their ability to promote ANH conferred no benefits on cognitive function, which was conflict with the majority viewpoints that AHN was participant in hippocampal-related cognition to some extend [21,3]. The mechanisms to ameliorate $\mathrm{CCH}$-generated cognitive deficits mainly concentrated on two aspects. On one hand, increased BDNF levels caused by EE and genetical injection contributed to better cognitive performance, which might because BDNF exhibited potent effects on prevention of cell death, improvement in synaptic functions, and promoting of neuronal function, and gradually improved learning and memory [27]. On the other hand, we suggested that astrocyte reactivities was negatively related to cognitive function, explaining that EE was superior to AAV-hTET1 in CCH-induced cognitive impairments, because EE showed less activated astrocytes, but AAV-hTET1 displayed more activated astrocytes. Further, astrocytes mediated considerably the effect of neurons, presynaptic function, and microglia on cognitive functions. Our results are consistent with previous findings that astrocytes 
were of great importance to modulate the local neuronal circuit balance, synaptic physiology, energy metabolism and mutual cooperation with microglia $[28,29]$, which made astrocytes to be an integral player in the pathogenesis of many brain diseases, such as alzheimer's disease, and parkinson's disease $[28,30,31]$. Future attempts to create new pharmacology should regard the benefits of healthy local neuronal environment, especially containing increased BDNF and less activated astrocytes, might provide a potentially means for improving cognition in $\mathrm{CCH}$.

At the same time, the present study revealed that more neuronal and presynaptic function were correlated with less depressive disorders, consistent with other researches [32,33]. EE increased the SYP levels, the AAV-hTET1 decreased the SYP levels, and SYP mediated the role of NEUN in the depressive performance, partly explaining that treatment with EE performed better in deal with depressive dysfunction than AAV-hTET1, protecting the rats from the detrimental depressive effects of $\mathrm{CCH}$. Interestingly, we argued that the glial activation might be a vital driving force for the deterioration of depression. It had been mentioned that repeated exposure to neuropathological stimuli causes dysregulation of microglia and astroglia, resulting in abnormal release of cytokine in the brain and aberrant synaptic interactions, providing possibility to develop depressive disorders [12,34,31]. To support this, we demonstrated astroglia and microglia activation was strongly correlated with severe depressive symptoms. AAV-hTET1 showed synchronous activation of microglia and astrocytes, while EE exhibited decreased astrocyte activity, devoting to the divergent depressive phenotypes that EE was more resistant to depression but AAV-hTET1 was more susceptibility to depression in response to $\mathrm{CCH}$. More importantly, causal mediation analysis showed significant mediation by presence of reactive glial cells in the relation between neural plasticity (NEUN and SYP) and depressive symptoms. Of note, the astroglia reaction to depression was mediated by microglial activation to a certain degree. Studies have shown that perturbations astrocyte and microglia resulted in neuronal and synapses deficits by contact dependent mechanisms [34,35], gradually making an effect on depressive-like behaviors. Thus, our study highlighted the importance of taking glial activation in consideration as promising strategies for depressive-like symptoms in $\mathrm{CCH}$.

These original findings have certain limitations. In total, a remarkable predominance of the vascular dysregulation component over the other AD pathologic biomarkers, accompanied by $\sim 80 \%$ of vascular factor more abnormal across all brain regions and time points than [5], which provided evidence for long-term vascular dysfunction in the development of the AD. Our research focused on the early stage of hypoperfusion-induced mild cognitive impairment. So, studies using animal models with long-term chronic ischemia would be able to address this particular question with disease progression. The work was also lack of special signaling to identify the changes in adult hippocampal neurogenesis and glial reactivity by genetical treatment or enhanced environment.

In summary, stimulating ANH through genetical treatment or EE was not sufficient for ameliorating the cognitive dysfunction and depressive-like behaviors. Healthy local brain environment with elevated BDNF and less astroglial reaction was conducive to improve cognitive dysfunction. Meanwhile, depressive disturbances were determined by astroglial and microglial activation, as well as neuronal and presynaptic function. EE performed better than hTET1 treatment for cognitive deficits and depression via glial activation in $\mathrm{CCH}$ (Fig. 8). We hope future work will describe potential signaling which links the curative methods (e.g AAV-hTET1 injection or enriched environment) and subsequent glial reactivity to cognitive and mental disturbances resulted from $\mathrm{CCH}$, finally providing valuable tools for the overall management of chronic cerebral ischemia patients.

\section{Abbreviations}

$\mathrm{CCH}$, chronic cerebral hypoperfusion; AHN, adult hippocampal neurogenesis; DG, dentate gyrus; NSC, neural stem cell; 2-VO, bilateral occlusion of common carotid artery; TET1, ten-eleven translocation methylcytosine dioxygenase 1; EE, environmental enrichment; AAV, adeno-associated viral; BrdU, 5-bromo-2deoxyuridine; SPT, sucrose preference test; OFT, open field test; NOR, novel object recognition test; MWM, Morris water maze; PBS, phosphate-buffered saline

\section{Declarations}

\section{Funding}

The study was financially supported by National Natural Science Foundation of China (No. 81771151 and No.82071210).

\section{Conflicts of interest}

The authors declare no conflict of interest.

\section{Availability of data and material}

The authors hereby declare that the generated datasets in this study will be presented upon request from the corresponding author.

\section{Authors' contributions}

Yaqing Li involved in study design, performing the study, drafting and revising the manuscript. Chujie Qu, Tian Li and Jiaxin Zheng involved in data analysis and performing the animal study. Hao Song, Linling Xu and Changhua Qu involved in data analysis. Nao Yan and Liyang Wu involved in performing the animal study. Junjian Zhang involved in study design and obtaining funding. All authors contributed to manuscript revision, read and approved the submitted version.

\section{Ethics approval}

Experimental procedures were approved by the Animal Ethics Committee of the Medical School of Wuhan University (Protocol 2018046) following the protocols of National Institutes of Health Guide for the Care and Use of Laboratory Animals.

\section{Consent for Publication}


Not applicable.

\section{Consent to Participate}

Not applicable.

\section{Acknowledgements}

Yaqing Li involved in study design, performing the study, drafting and revising the manuscript. Chujie Qu, Tian Li and Jiaxin Zheng involved in data analysis and performing the animal study. Hao Song, Linling Xu and Changhua Qu involved in data analysis. Nao Yan and Liyang Wu involved in performing the animal study. Junjian Zhang involved in study design and obtaining funding. All authors contributed to manuscript revision, read and approved the submitted version. The study was financially supported by National Natural Science Foundation of China (No. 81771151 and No.82071210).

\section{References}

1. Arvanitakis Z, Shah RC, Bennett DA (2019) Diagnosis and Management of Dementia: Review. JAMA 322 (16):1589-

1599. https://doi.org/10.1001/jama.2019.4782

2. Raz L, Knoefel J, Bhaskar K (2016) The neuropathology and cerebrovascular mechanisms of dementia. J Cereb Blood Flow Metab 36 (1):172186. https://doi.org/10.1038/jcbfm.2015.164

3. Berger T, Lee H, Young AH, Aarsland D, Thuret S (2020) Adult Hippocampal Neurogenesis in Major Depressive Disorder and Alzheimer's Disease. Trends Mol Med 26 (9):803-818. https://doi.org/10.1016/j.molmed.2020.03.010

4. van Agtmaal MJM, Houben A, Pouwer F, Stehouwer CDA, Schram MT (2017) Association of Microvascular Dysfunction With Late-Life Depression: A Systematic Review and Meta-analysis. JAMA Psychiatry 74 (7):729-739. https://doi.org/10.1001/jamapsychiatry.2017.0984

5. Iturria-Medina Y, Sotero RC, Toussaint PJ, Mateos-Perez JM, Evans AC, Alzheimer's Disease Neuroimaging I (2016) Early role of vascular dysregulation on late-onset Alzheimer's disease based on multifactorial data-driven analysis. Nat Commun 7:11934. https://doi.org/10.1038/ncomms11934

6. Farkas E, Obrenovitch TP, Institoris A, Bari F (2011) Effects of early aging and cerebral hypoperfusion on spreading depression in rats. Neurobiol Aging 32 (9):1707-1715. https://doi.org/10.1016/j.neurobiolaging.2009.10.002

7. Lee SR, Choi B, Paul S, Seo JH, Back DB, Han JS, Choi DH, Kwon KJ, Shin CY, Lee J, Han SH, Kim HY (2015) Depressive-like behaviors in a rat model of chronic cerebral hypoperfusion. Transl Stroke Res 6 (3):207-214. https://doi.org/10.1007/s12975-014-0385-3

8. Bonaguidi MA, Wheeler MA, Shapiro JS, Stadel RP, Sun GJ, Ming GL, Song H (2011) In vivo clonal analysis reveals self-renewing and multipotent adult neural stem cell characteristics. Cell 145 (7):1142-1155. https://doi.org/10.1016/j.cell.2011.05.024

9. Choi SH, Bylykbashi E, Chatila ZK, Lee SW, Pulli B, Clemenson GD, Kim E, Rompala A, Oram MK, Asselin C, Aronson J, Zhang C, Miller SJ, Lesinski A, Chen JW, Kim DY, van Praag H, Spiegelman BM, Gage FH, Tanzi RE (2018) Combined adult neurogenesis and BDNF mimic exercise effects on cognition in an Alzheimer's mouse model. Science 361 (6406). https://doi.org/10.1126/science.aan8821

10. Boldrini M, Galfalvy H, Dwork AJ, Rosoklija GB, Trencevska-Ivanovska I, Pavlovski G, Hen R, Arango V, Mann JJ (2019) Resilience Is Associated With Larger Dentate Gyrus, While Suicide Decedents With Major Depressive Disorder Have Fewer Granule Neurons. Biol Psychiatry 85 (10):850-

862. https://doi.org/10.1016/j.biopsych.2018.12.022

11. Snyder JS, Soumier A, Brewer M, Pickel J, Cameron HA (2011) Adult hippocampal neurogenesis buffers stress responses and depressive behaviour. Nature 476 (7361):458-461. https://doi.org/10.1038/nature10287

12. Fan C, Song Q, Wang P, Li Y, Yang M, Yu SY (2018) Neuroprotective Effects of Ginsenoside-Rg1 Against Depression-Like Behaviors via Suppressing Glial Activation, Synaptic Deficits, and Neuronal Apoptosis in Rats. Front Immunol 9:2889. https://doi.org/10.3389/fimmu.2018.02889

13. Hsu ET, Gangolli M, Su S, Holleran L, Stein TD, Alvarez VE, McKee AC, Schmidt RE, Brody DL (2018) Astrocytic degeneration in chronic traumatic encephalopathy. Acta Neuropathol 136 (6):955-972. https://doi.org/10.1007/s00401-018-1902-3

14. Verkhratsky A, Zorec R, Rodriguez JJ, Parpura V (2016) Astroglia dynamics in ageing and Alzheimer's disease. Curr Opin Pharmacol 26:74-

79. https://doi.org/10.1016/j.coph.2015.09.011

15. Rangaraju S, Dammer EB, Raza SA, Rathakrishnan P, Xiao H, Gao T, Duong DM, Pennington MW, Lah JJ, Seyfried NT, Levey Al (2018) Identification and therapeutic modulation of a pro-inflammatory subset of disease-associated-microglia in Alzheimer's disease. Mol Neurodegener 13

(1):24. https://doi.org/10.1186/s13024-018-0254-8

16. Hopperton KE, Mohammad D, Trepanier MO, Giuliano V, Bazinet RP (2018) Markers of microglia in post-mortem brain samples from patients with Alzheimer's disease: a systematic review. Mol Psychiatry 23 (2):177-198. https://doi.org/10.1038/mp.2017.246 
17. Enache D, Pariante CM, Mondelli V (2019) Markers of central inflammation in major depressive disorder: A systematic review and meta-analysis of studies examining cerebrospinal fluid, positron emission tomography and post-mortem brain tissue. Brain Behav Immun 81:24-

40. https://doi.org/10.1016/j.bbi.2019.06.015

18. Lv WJ, Liu C, Yu LZ, Zhou JH, Li Y, Xiong Y, Guo A, Chao LM, Qu Q, Wei GW, Tang XG, Yin YL, Guo SN (2020) Melatonin Alleviates Neuroinflammation and Metabolic Disorder in DSS-Induced Depression Rats. Oxid Med Cell Longev 2020:1241894. https://doi.org/10.1155/2020/1241894

19. Zhang RR, Cui QY, Murai K, Lim YC, Smith ZD, Jin S, Ye P, Rosa L, Lee YK, Wu HP, Liu W, Xu ZM, Yang L, Ding YQ, Tang F, Meissner A, Ding C, Shi Y, Xu GL (2013) Tet1 regulates adult hippocampal neurogenesis and cognition. Cell Stem Cell 13 (2):237-245. https://doi.org/10.1016/j.stem.2013.05.006

20. Guo JU, Su Y, Zhong C, Ming GL, Song H (2011) Hydroxylation of 5-methylcytosine by TET1 promotes active DNA demethylation in the adult brain. Cell 145 (3):423-434. https://doi.org/10.1016/j.cell.2011.03.022

21. Cope EC, Gould E (2019) Adult Neurogenesis, Glia, and the Extracellular Matrix. Cell Stem Cell 24 (5):690-705. https://doi.org/10.1016/j.stem.2019.03.023

22. Xu H, Rajsombath MM, Weikop P, Selkoe DJ (2018) Enriched environment enhances beta-adrenergic signaling to prevent microglia inflammation by amyloid-beta. EMBO Mol Med 10 (9). https://doi.org/10.15252/emmm.201808931

23. Rahati M, Nozari M, Eslami H, Shabani M, Basiri M (2016) Effects of enriched environment on alterations in the prefrontal cortex GFAP-and S100Bimmunopositive astrocytes and behavioral deficits in MK-801-treated rats. Neuroscience 326:105-116. https://doi.org/10.1016/j.neuroscience.2016.03.065

24. Chabry J, Nicolas S, Cazareth J, Murris E, Guyon A, Glaichenhaus N, Heurteaux C, Petit-Paitel A (2015) Enriched environment decreases microglia and brain macrophages inflammatory phenotypes through adiponectin-dependent mechanisms: Relevance to depressive-like behavior. Brain Behav Immun 50:275287. https://doi.org/10.1016/j.bbi.2015.07.018

25. Cai W, Xue C, Sakaguchi M, Konishi M, Shirazian A, Ferris HA, Li ME, Yu R, Kleinridders A, Pothos EN, Kahn CR (2018) Insulin regulates astrocyte gliotransmission and modulates behavior. J Clin Invest 128 (7):2914-2926. https://doi.org/10.1172/JCI99366

26. Farkas E, Donka G, de Vos RA, Mihaly A, Bari F, Luiten PG (2004) Experimental cerebral hypoperfusion induces white matter injury and microglial activation in the rat brain. Acta Neuropathol 108 (1):57-64. https://doi.org/10.1007/s00401-004-0864-9

27. Nagahara AH, Tuszynski MH (2011) Potential therapeutic uses of BDNF in neurological and psychiatric disorders. Nat Rev Drug Discov 10 (3):209219. https://doi.org/10.1038/nrd3366

28. Osborn LM, Kamphuis W, Wadman WJ, Hol EM (2016) Astrogliosis: An integral player in the pathogenesis of Alzheimer's disease. Prog Neurobiol 144:121141. https://doi.org/10.1016/j.pneurobio.2016.01.001

29. Liu LR, Liu JC, Bao JS, Bai QQ, Wang GQ (2020) Interaction of Microglia and Astrocytes in the Neurovascular Unit. Front Immunol 11:1024. https://doi.org/10.3389/fimmu.2020.01024

30. Kam TI, Hinkle JT, Dawson TM, Dawson VL (2020) Microglia and astrocyte dysfunction in parkinson's disease. Neurobiol Dis 144:105028. https://doi.org/10.1016/j.nbd.2020.105028

31. Dallerac G, Rouach N (2016) Astrocytes as new targets to improve cognitive functions. Prog Neurobiol 144:4867. https://doi.org/10.1016/j.pneurobio.2016.01.003

32. Liu W, Xue X, Xia J, Liu J, Qi Z (2018) Swimming exercise reverses CUMS-induced changes in depression-like behaviors and hippocampal plasticity-related proteins. J Affect Disord 227:126-135. https://doi.org/10.1016/j.jad.2017.10.019

33. Han SK, Joo MK, Kim JK, Jeung W, Kang H, Kim DH (2020) Bifidobacteria-Fermented Red Ginseng and Its Constituents Ginsenoside Rd and Protopanaxatriol Alleviate Anxiety/Depression in Mice by the Amelioration of Gut Dysbiosis. Nutrients 12 (4). https://doi.org/10.3390/nu12040901

34. Wohleb ES, Franklin T, Iwata M, Duman RS (2016) Integrating neuroimmune systems in the neurobiology of depression. Nat Rev Neurosci 17 (8):497511. https://doi.org/10.1038/nrn.2016.69

35. Tremblay ME, Lowery RL, Majewska AK (2010) Microglial interactions with synapses are modulated by visual experience. PLoS Biol 8

(11):e1000527. https://doi.org/10.1371/journal.pbio.1000527

\section{Tables}

Table 1. Association analysis among adult neurogenesis, synaptic markers, glial activation and cognitive functions 


\begin{tabular}{|c|c|c|c|c|c|c|c|c|c|c|c|c|c|c|}
\hline \multirow[b]{2}{*}{ Marker } & \multicolumn{2}{|c|}{$\begin{array}{l}\text { Novel object } \\
\text { recognition test }\end{array}$} & \multicolumn{2}{|l|}{$\begin{array}{l}\text { Morris water } \\
\text { maze-Day } 1\end{array}$} & \multicolumn{2}{|l|}{$\begin{array}{l}\text { Morris water } \\
\text { maze-Day } 2\end{array}$} & \multicolumn{2}{|l|}{$\begin{array}{l}\text { Morris water } \\
\text { maze-Day } 3\end{array}$} & \multicolumn{2}{|c|}{$\begin{array}{l}\text { Morris water } \\
\text { maze-Day } 4\end{array}$} & \multicolumn{2}{|c|}{$\begin{array}{l}\text { Morris water } \\
\text { maze-Day } 5\end{array}$} & \multicolumn{2}{|c|}{$\begin{array}{l}\text { Morris water } \\
\text { maze-Day } 6\end{array}$} \\
\hline & $\begin{array}{l}\text { Beta } \\
(95 \% \mathrm{Cl})\end{array}$ & $\mathrm{P}$ & $\begin{array}{l}\text { Beta } \\
(95 \% \mathrm{Cl})\end{array}$ & $\mathrm{P}$ & $\begin{array}{l}\text { Beta } \\
(95 \% \mathrm{Cl})\end{array}$ & $\mathrm{P}$ & $\begin{array}{l}\text { Beta } \\
(95 \% \mathrm{Cl})\end{array}$ & $\mathrm{P}$ & $\begin{array}{l}\text { Beta } \\
(95 \% \mathrm{Cl})\end{array}$ & $\mathrm{P}$ & $\begin{array}{l}\text { Beta } \\
(95 \% \mathrm{Cl})\end{array}$ & $\mathrm{P}$ & $\begin{array}{l}\text { Beta } \\
(95 \% \mathrm{Cl})\end{array}$ & $\mathrm{P}$ \\
\hline SYP & $\begin{array}{l}0.09 \\
(-0.07 \text { to } \\
0.25)\end{array}$ & 0.30 & $\begin{array}{l}4.85(-3.12 \\
\text { to } 12.81)\end{array}$ & 0.24 & $\begin{array}{l}1.71(-8.97 \\
\text { to } 12.38)\end{array}$ & 0.76 & $\begin{array}{l}5.37(-4.06 \\
\text { to } 14.80)\end{array}$ & 0.27 & $\begin{array}{l}-2.75 \\
(-10.74 \\
\text { to } 5.23)\end{array}$ & 0.51 & $\begin{array}{l}1.43 \\
(-5.94 \text { to } \\
8.79)\end{array}$ & 0.71 & $\begin{array}{l}-1.61 \\
(-6.62 \\
\text { to } 3.40 \\
)\end{array}$ & 0.53 \\
\hline PSD95 & $\begin{array}{l}-0.01 \\
(-0.08 \text { to } \\
0.05)\end{array}$ & 0.70 & $\begin{array}{l}-0.57(-3.68 \\
\text { to } 2.54)\end{array}$ & 0.72 & $\begin{array}{l}-0.14 \\
(-4.13 \text { to } \\
3.85)\end{array}$ & 0.95 & $\begin{array}{l}-0.08 \\
(-3.36 \text { to } \\
3.20)\end{array}$ & 0.96 & $\begin{array}{l}-0.06 \\
(-3.36 \text { to } \\
3.25)\end{array}$ & 0.97 & $\begin{array}{l}-1.55 \\
(-3.93 \text { to } \\
0.82)\end{array}$ & 0.21 & $\begin{array}{l}0.30 \\
(-1.85 \\
\text { to } 2.45 \\
)\end{array}$ & 0.78 \\
\hline BDNF & $\begin{array}{l}0.08 \\
(-0.17 \text { to } \\
0.33)\end{array}$ & 0.52 & $\begin{array}{l}-14.17 \\
(-25.50 \text { to } \\
-2.84)\end{array}$ & 0.02 & $\begin{array}{l}-1.55 \\
(-17.93 \text { to } \\
14.84)\end{array}$ & 0.86 & $\begin{array}{l}-13.85 \\
(-27.68 \text { to } \\
-0.01)\end{array}$ & 0.06 & $\begin{array}{l}-9.27 \\
(-21.10 \\
\text { to } 2.57)\end{array}$ & 0.14 & $\begin{array}{l}-10.14 \\
(-20.79 \\
\text { to } 0.51)\end{array}$ & 0.07 & $\begin{array}{l}0.85 \\
(-6.88 \\
\text { to } 8.58 \\
)\end{array}$ & 0.83 \\
\hline PCNA & $\begin{array}{l}0.00 \\
(-0.05 \text { to } \\
0.05)\end{array}$ & 0.92 & $\begin{array}{l}0.18(-2.31 \\
\text { to } 2.67)\end{array}$ & 0.89 & $\begin{array}{l}0.37(-2.88 \\
\text { to } 3.62)\end{array}$ & 0.82 & $\begin{array}{l}-1.66 \\
(-4.59 \text { to } \\
1.27)\end{array}$ & 0.28 & $\begin{array}{l}-0.62 \\
(-3.07 \text { to } \\
1.84)\end{array}$ & 0.63 & $\begin{array}{l}-1.49 \\
(-3.69 \text { to } \\
0.71)\end{array}$ & 0.20 & $\begin{array}{l}0.37 \\
(-1.17 \\
\text { to } 1.91 \\
)\end{array}$ & 0.64 \\
\hline DCX & $\begin{array}{l}0.05 \\
(-0.06 \text { to } \\
0.16)\end{array}$ & 0.37 & $\begin{array}{l}-3.50(-8.75 \\
\text { to } 1.74)\end{array}$ & 0.20 & $\begin{array}{l}3.00(-4.18 \\
\text { to } 10.17)\end{array}$ & 0.42 & $\begin{array}{l}-0.03 \\
(-6.47 \text { to } \\
6.41)\end{array}$ & 0.99 & $\begin{array}{l}-2.75 \\
(-8.44 \text { to } \\
2.93)\end{array}$ & 0.35 & $\begin{array}{l}-0.62 \\
(-5.50 \text { to } \\
4.27)\end{array}$ & 0.81 & $\begin{array}{l}0.07 \\
(-3.86 \\
\text { to } 4.01 \\
)\end{array}$ & 0.97 \\
\hline NEUN & $\begin{array}{l}0.12 \\
(-0.05 \text { to } \\
0.29)\end{array}$ & 0.18 & $\begin{array}{l}-0.11(-8.63 \\
\text { to } 8.40)\end{array}$ & 0.98 & $\begin{array}{l}-5.36 \\
(-16.72 \text { to } \\
6.00)\end{array}$ & 0.36 & $\begin{array}{l}-1.50 \\
(-11.41 \text { to } \\
8.40)\end{array}$ & 0.77 & $\begin{array}{l}-3.57 \\
(-13.42 \\
\text { to } 6.28)\end{array}$ & 0.48 & $\begin{array}{l}1.17 \\
(-6.57 \text { to } \\
8.91)\end{array}$ & 0.77 & $\begin{array}{l}3.17 \\
(-3.06 \\
\text { to } 9.40 \\
)\end{array}$ & 0.33 \\
\hline IBA1 & $\begin{array}{l}-0.05 \\
(-0.14 \text { to } \\
0.05)\end{array}$ & 0.34 & $\begin{array}{l}-0.39(-4.92 \\
\text { to } 4.14)\end{array}$ & 0.87 & $\begin{array}{l}-3.37 \\
(-9.36 \text { to } \\
2.63)\end{array}$ & 0.28 & $\begin{array}{l}0.30(-5.12 \\
\text { to } 5.72)\end{array}$ & 0.91 & $\begin{array}{l}1.85 \\
(-2.96 \text { to } \\
6.66)\end{array}$ & 0.46 & $\begin{array}{l}-0.46 \\
(-4.58 \text { to } \\
3.65)\end{array}$ & 0.83 & $\begin{array}{l}-0.29 \\
(-3.60 \\
\text { to } 3.02 \\
)\end{array}$ & 0.87 \\
\hline GFAP & $\begin{array}{l}-0.04 \\
(-0.16 \text { to } \\
0.07)\end{array}$ & 0.44 & $\begin{array}{l}-3.67(-9.47 \\
\text { to } 2.13)\end{array}$ & 0.22 & $\begin{array}{l}-0.36 \\
(-8.39 \text { to } \\
7.67)\end{array}$ & 0.93 & $\begin{array}{l}-4.91 \\
(-11.59 \text { to } \\
1.76)\end{array}$ & 0.16 & $\begin{array}{l}1.02 \\
(-5.89 \text { to } \\
7.92)\end{array}$ & 0.77 & $\begin{array}{l}-6.67 \\
(-11.17 \\
\text { to }-2.17)\end{array}$ & 0.01 & $\begin{array}{l}0.66 \\
(-3.33 \\
\text { to } 4.64 \\
)\end{array}$ & 0.75 \\
\hline
\end{tabular}

Model: adjusted for group.

Table 2. Association analysis among adult neurogenesis, synaptic markers, glial activation and depressive-like behaviors

\begin{tabular}{|lllllllll|}
\hline Marker & Sucrose preference test & OFT-crossing numbers & & \multicolumn{2}{l|}{ OFT-grooming time } & & OFT-rearing numbers \\
\hline & Beta $(95 \% \mathrm{Cl})$ & $\mathrm{P}$ & Beta $(95 \% \mathrm{Cl})$ & $\mathrm{P}$ & Beta $(95 \% \mathrm{Cl})$ & $\mathrm{P}$ & Beta $(95 \% \mathrm{Cl})$ \\
\hline SYP & $0.21(0.04$ to 0.37$)$ & 0.02 & $26.67(-7.83$ to 61.18$)$ & 0.14 & $9.56(-1.67$ to 20.79$)$ & 0.11 & $6.23(-2.29$ to 14.76$)$ & 0.16 \\
\hline PSD95 & $-0.02(-0.09$ to 0.04$)$ & 0.47 & $5.14(-6.80$ to 17.07$)$ & 0.40 & $-3.81(-9.77$ to 2.15$)$ & 0.22 & $-0.29(-2.90$ to 2.33$)$ & 0.83 \\
\hline BDNF & $-0.34(-0.59$ to -0.09$)$ & 0.01 & $-33.84(-87.43$ to 19.76$)$ & 0.23 & $-10.84(-28.44$ to 6.77$)$ & 0.24 & $-8.83(-21.97$ to 4.32$)$ & 0.20 \\
\hline PCNA & $0.00(-0.06$ to 0.06$)$ & 0.98 & $9.33(-1.28$ to 19.93$)$ & 0.10 & $0.10(-4.19$ to 4.38$)$ & 0.97 & $0.01(-2.70$ to 2.72$)$ & 0.99 \\
\hline DCX & $-0.03(-0.16$ to 0.09$)$ & 0.61 & $1.98(-22.03$ to 25.99$)$ & 0.87 & $-7.58(-17.07$ to 1.90$)$ & 0.13 & $-3.86(-9.51$ to 1.78$)$ & 0.19 \\
\hline NEUN & $0.08(-0.11$ to 0.26$)$ & 0.43 & $23.10(-13.04$ to 59.24$)$ & 0.22 & $20.30(3.54$ to 37.06$)$ & 0.02 & $4.33(-4.39$ to 13.06$)$ & 0.34 \\
\hline IBA1 & $-0.15(-0.24$ to -0.06$)$ & $<0.01$ & $-27.97(-45.72$ to -10.22$)$ & $<0.01$ & $-2.39(-10.63$ to 5.85$)$ & 0.57 & $-4.78(-9.37$ to -0.18$)$ & $<0.05$ \\
\hline GFAP & $-0.15(-0.27$ to -0.03$)$ & 0.02 & $-29.27(-52.69$ to -5.85$)$ & 0.02 & $-5.64(-16.54$ to 5.26$)$ & 0.32 & $-6.58(-12.21$ to -0.95$)$ & 0.03 \\
\hline
\end{tabular}

Model: adjusted for group.

Table 3. Association analysis among adult neurogenesis, synaptic markers and glial activation 


\begin{tabular}{|c|c|c|c|c|c|c|c|c|c|c|c|c|c|c|c|}
\hline Marker & SYP & & PSD95 & & BDNF & & PCNA & & DCX & & NeuN & & IBA1 & & GFAP \\
\hline & $\begin{array}{l}\text { Beta } \\
(95 \% \mathrm{Cl})\end{array}$ & $\mathrm{P}$ & $\begin{array}{l}\text { Beta } \\
(95 \% \mathrm{Cl})\end{array}$ & $\mathrm{P}$ & $\begin{array}{l}\text { Beta } \\
(95 \% \mathrm{Cl})\end{array}$ & $P$ & $\begin{array}{l}\text { Beta } \\
(95 \% \mathrm{Cl})\end{array}$ & $\mathrm{P}$ & $\begin{array}{l}\text { Beta } \\
(95 \% \mathrm{Cl})\end{array}$ & $\mathrm{P}$ & $\begin{array}{l}\text { Beta } \\
(95 \% \mathrm{Cl})\end{array}$ & $\mathrm{P}$ & $\begin{array}{l}\text { Beta } \\
(95 \% \mathrm{Cl})\end{array}$ & $\mathrm{P}$ & $\begin{array}{l}\text { Beta } \\
(95 \% \mathrm{Cl})\end{array}$ \\
\hline SYP & NA & NA & $\begin{array}{l}-0.26 \\
(-0.86 \\
\text { to } 0.35 \\
)\end{array}$ & 0.41 & $\begin{array}{l}-0.03 \\
(-0.28 \\
\text { to } 0.21 \\
)\end{array}$ & 0.80 & $\begin{array}{l}0.05 \\
(-1.16 \\
\text { to } 1.27 \\
)\end{array}$ & 0.93 & $\begin{array}{l}-0.07 \\
(-0.57 \\
\text { to } 0.43 \\
)\end{array}$ & 0.78 & $\begin{array}{l}0.21 \\
(0.02 \text { to } \\
0.41)\end{array}$ & 0.04 & $\begin{array}{l}-0.94 \\
(-1.42 \\
\text { to }-0.47 \\
)\end{array}$ & $<0.01$ & $\begin{array}{l}-0.58 \\
(-0.94 \\
\text { to }-0.21 \\
)\end{array}$ \\
\hline PSD95 & $\begin{array}{l}-0.10 \\
(-0.33 \\
\text { to } 0.13 \\
)\end{array}$ & 0.41 & NA & NA & $\begin{array}{l}0.10 \\
(-0.05 \\
\text { to } 0.24 \\
)\end{array}$ & 0.21 & $\begin{array}{l}0.07 \\
(-0.67 \\
\text { to } 0.81 \\
)\end{array}$ & 0.86 & $\begin{array}{l}-0.06 \\
(-0.34 \\
\text { to } 0.23 \\
)\end{array}$ & 0.71 & $\begin{array}{l}-0.08 \\
(-0.21 \\
\text { to } 0.06 \\
)\end{array}$ & 0.25 & $\begin{array}{l}0.10 \\
(-0.24 \\
\text { to } 0.44 \\
)\end{array}$ & 0.55 & $\begin{array}{l}0.03 \\
(-0.22 \\
\text { to } 0.27 \\
)\end{array}$ \\
\hline BDNF & $\begin{array}{l}-0.08 \\
(-0.65 \\
\text { to } 0.50 \\
)\end{array}$ & 0.80 & $\begin{array}{l}0.60 \\
(-0.31 \\
\text { to } 1.50 \\
)\end{array}$ & 0.21 & NA & NA & $\begin{array}{l}-1.09 \\
(-2.91 \\
\text { to } 0.73 \\
)\end{array}$ & 0.25 & $\begin{array}{l}0.45 \\
(-0.29 \\
\text { to } 1.20 \\
)\end{array}$ & 0.25 & $\begin{array}{l}-0.02 \\
(-0.34 \\
\text { to } 0.31 \\
)\end{array}$ & 0.92 & $\begin{array}{l}0.22 \\
(-0.69 \\
\text { to } 1.12 \\
)\end{array}$ & 0.64 & $\begin{array}{l}0.75 \\
(0.17 \text { to } \\
1.33)\end{array}$ \\
\hline PCNA & $\begin{array}{l}0.01 \\
(-0.11 \\
\text { to } 0.12 \\
)\end{array}$ & 0.93 & $\begin{array}{l}0.02 \\
(-0.17 \\
\text { to } 0.20 \\
)\end{array}$ & 0.86 & $\begin{array}{l}-0.05 \\
(-0.12 \\
\text { to } 0.03 \\
)\end{array}$ & 0.25 & NA & NA & $\begin{array}{l}0.21 \\
(0.07 \text { to } \\
0.34)\end{array}$ & 0.01 & $\begin{array}{l}0.04 \\
(-0.03 \\
\text { to } 0.10 \\
)\end{array}$ & 0.29 & $\begin{array}{l}0.00 \\
(-0.18 \\
\text { to } 0.18 \\
)\end{array}$ & 0.96 & $\begin{array}{l}0.01 \\
(-0.12 \\
\text { to } 0.14 \\
)\end{array}$ \\
\hline DCX & $\begin{array}{l}-0.04 \\
(-0.33 \\
\text { to } 0.24 \\
)\end{array}$ & 0.78 & $\begin{array}{l}-0.08 \\
(-0.50 \\
\text { to } 0.34 \\
)\end{array}$ & 0.71 & $\begin{array}{l}0.11 \\
(-0.07 \\
\text { to } 0.29 \\
)\end{array}$ & 0.25 & $\begin{array}{l}1.23 \\
(0.44 \text { to } \\
2.01)\end{array}$ & 0.01 & NA & NA & $\begin{array}{l}-0.02 \\
(-0.18 \\
\text { to } 0.14 \\
)\end{array}$ & 0.79 & $\begin{array}{l}0.19 \\
(-0.21 \\
\text { to } 0.60 \\
)\end{array}$ & 0.36 & $\begin{array}{l}0.20 \\
(-0.10 \\
\text { to } 0.50 \\
)\end{array}$ \\
\hline NeuN & $\begin{array}{l}0.98 \\
(0.35 \text { to } \\
1.60)\end{array}$ & 0.04 & $\begin{array}{l}-0.40 \\
(-1.08 \\
\text { to } 0.27 \\
)\end{array}$ & 0.25 & $\begin{array}{l}-0.02 \\
(-0.46 \\
\text { to } 0.42 \\
)\end{array}$ & 0.92 & $\begin{array}{l}1.14 \\
(-0.94 \\
\text { to } 3.23 \\
)\end{array}$ & 0.29 & $\begin{array}{l}-0.11 \\
(-0.86 \\
\text { to } 0.65 \\
)\end{array}$ & 0.79 & NA & NA & $\begin{array}{l}-1.21 \\
(-2.01 \\
\text { to }-0.41 \\
)\end{array}$ & 0.01 & $\begin{array}{l}-0.63 \\
(-1.07 \\
\text { to }-0.19 \\
)\end{array}$ \\
\hline IBA1 & $\begin{array}{l}-0.38 \\
(-0.57 \\
\text { to }-0.19 \\
)\end{array}$ & $<0.01$ & $\begin{array}{l}0.11 \\
(-0.24 \\
\text { to } 0.46 \\
)\end{array}$ & 0.55 & $\begin{array}{l}0.04 \\
(-0.12 \\
\text { to } 0.19 \\
)\end{array}$ & 0.64 & $\begin{array}{l}0.02 \\
(-0.74 \\
\text { to } 0.78 \\
)\end{array}$ & 0.96 & $\begin{array}{l}0.14 \\
(-0.15 \\
\text { to } 0.43 \\
)\end{array}$ & 0.36 & $\begin{array}{l}-0.18 \\
(-0.30 \\
\text { to }-0.06 \\
)\end{array}$ & 0.01 & NA & NA & $\begin{array}{l}0.46 \\
(0.26 \text { to } \\
0.66)\end{array}$ \\
\hline GFAP & $\begin{array}{l}-0.46 \\
(-0.75 \\
\text { to }-0.17 \\
)^{-}\end{array}$ & $<0.01$ & $\begin{array}{l}0.05 \\
(-0.38 \\
\text { to } 0.47 \\
)\end{array}$ & 0.84 & $\begin{array}{l}0.26 \\
(0.06 \text { to } \\
0.45)\end{array}$ & 0.02 & $\begin{array}{l}0.08 \\
(-0.99 \\
\text { to } 1.15 \\
)^{-}\end{array}$ & 0.88 & $\begin{array}{l}0.26 \\
(-0.12 \\
\text { to } 0.64 \\
)\end{array}$ & 0.19 & $\begin{array}{l}-0.28 \\
(-0.47 \\
\text { to }-0.08 \\
)^{-0}\end{array}$ & 0.01 & $\begin{array}{l}0.82 \\
(0.46 \text { to } \\
1.18)\end{array}$ & $<0.01$ & NA \\
\hline
\end{tabular}

Model: adjusted for group.

\section{Figures}



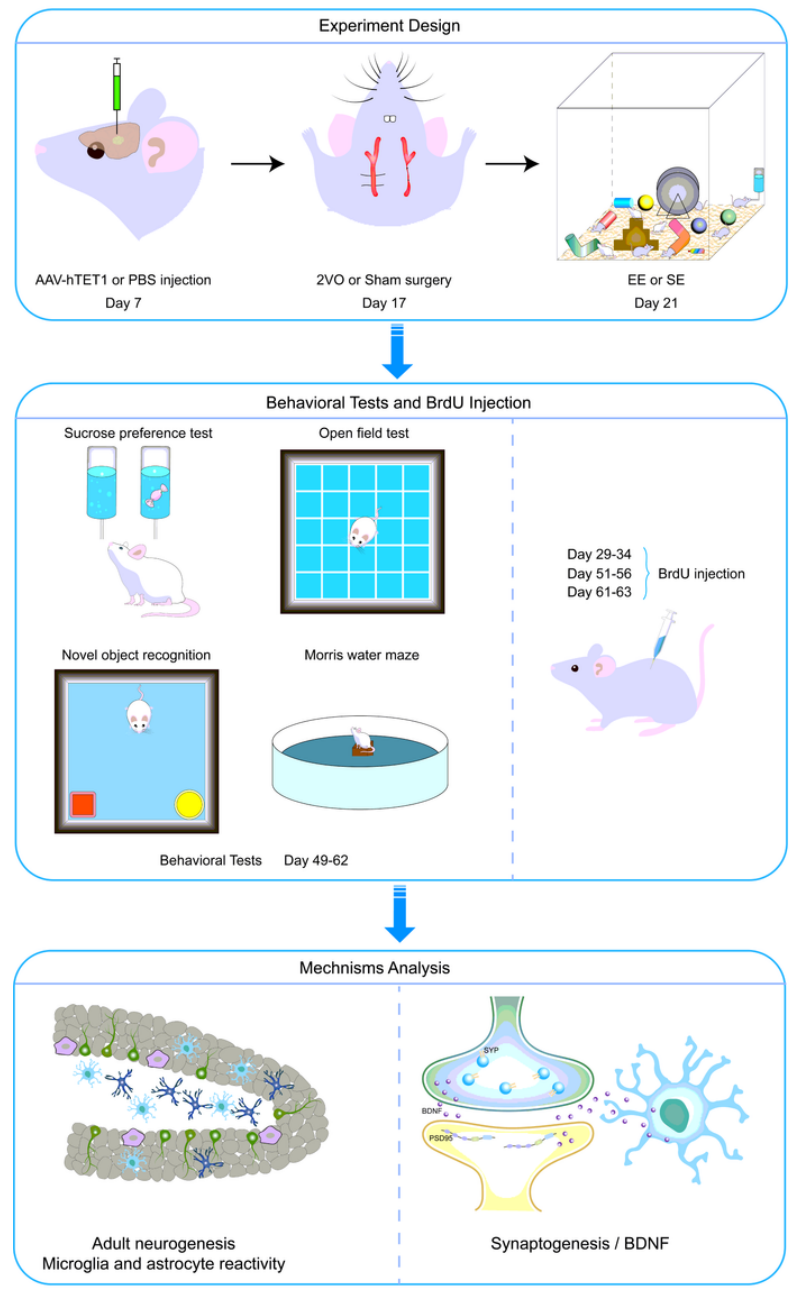

\section{Figure 1}

The experimental design. Abbreviations: AAV, adeno-associated viral; hTET1, human Ten-eleven translocation methylcytosine dioxygenase 1; PBS, phosphatebuffered saline; 2VO, bilateral common carotid artery occlusion; EE, enriched environment; SE, standard environment; BrdU, 5-bromo-2-deoxyuridine. 
Fig. 2

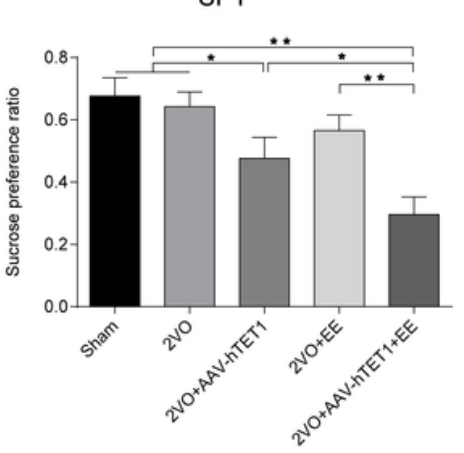

e

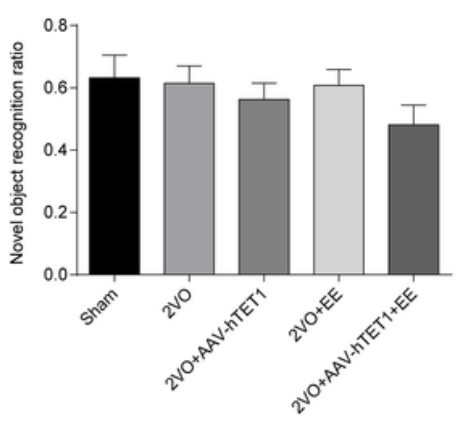

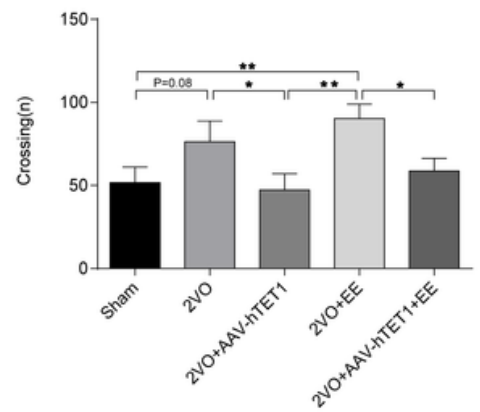

f

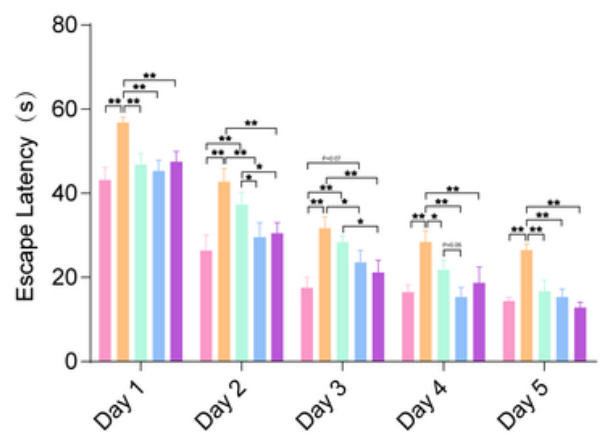

OFT

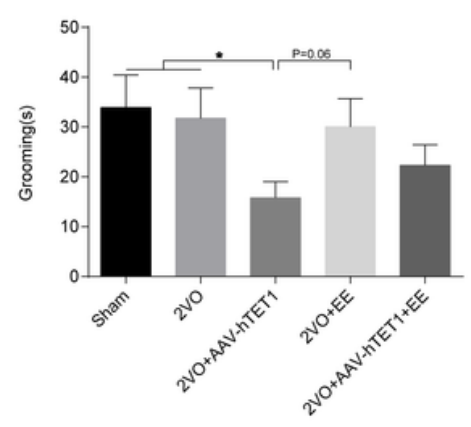

- Sham

- 2vo

2VO+AAV-hTET 1

- $2 \mathrm{VO}+\mathrm{EE}$

- 2VO+AAV-hTET1+EE d

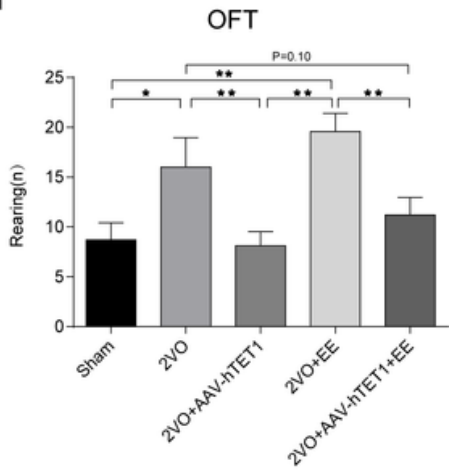

g

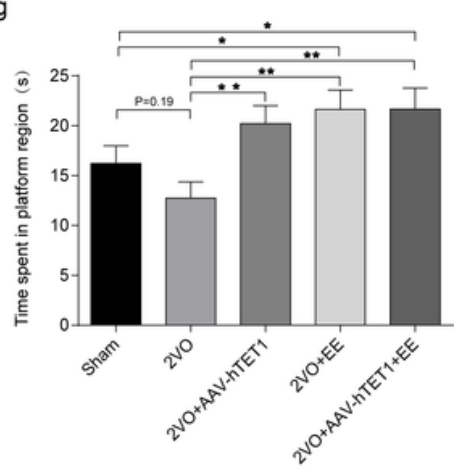

Figure 2

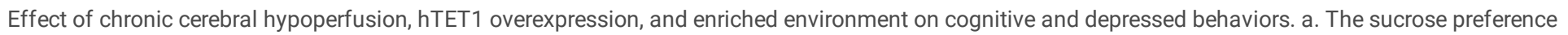

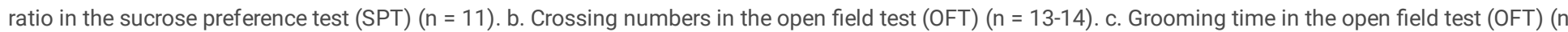

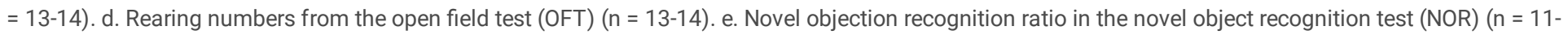

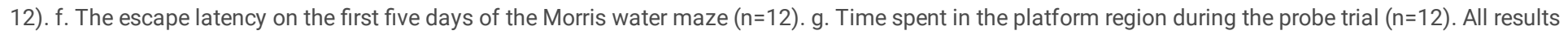

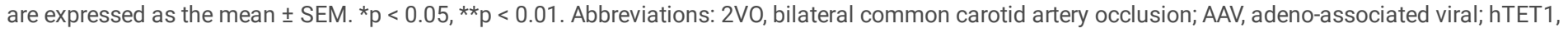
human Ten-eleven translocation methylcytosine dioxygenase 1; EE, enriched environment 

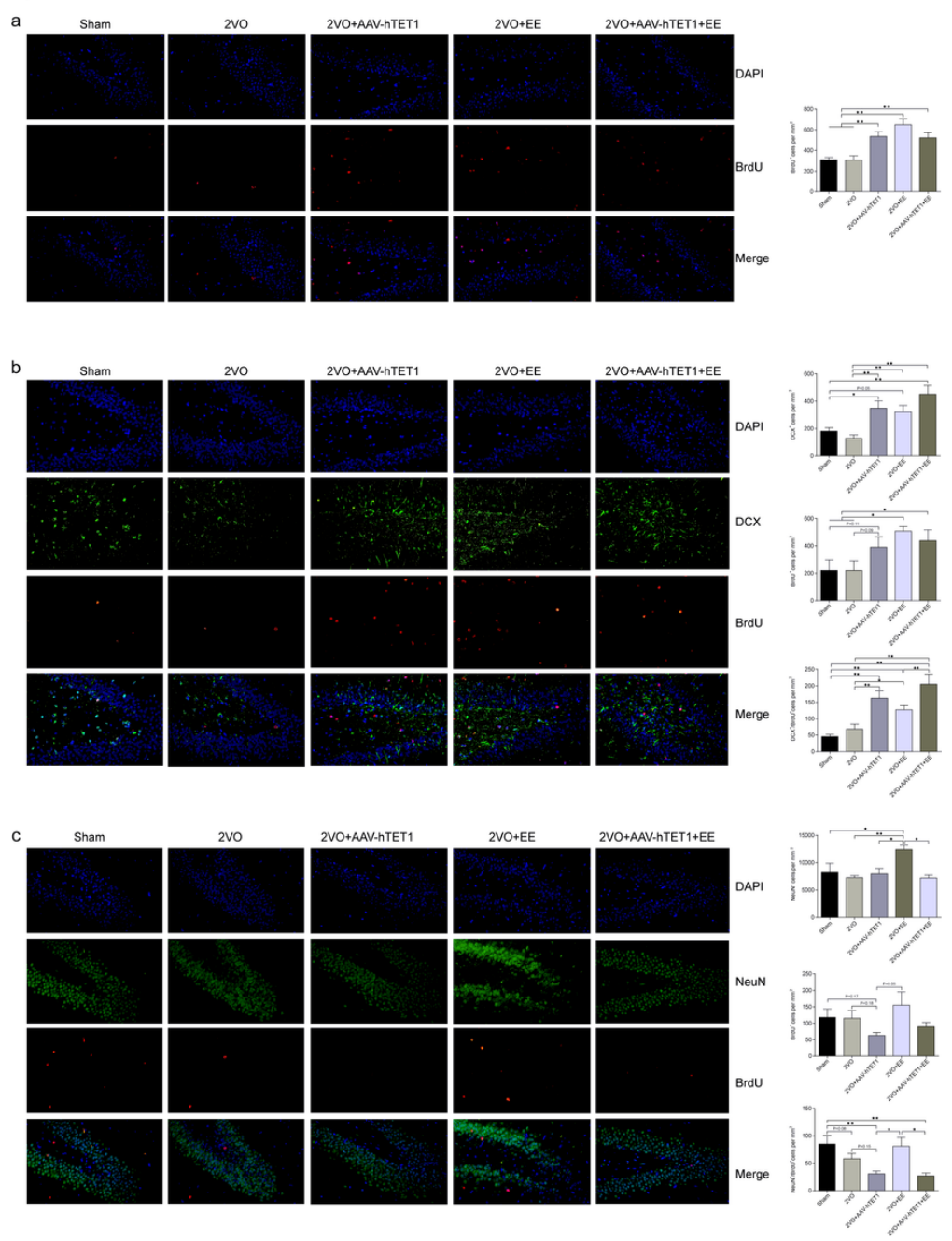

Figure 3

Effect of chronic cerebral hypoperfusion, hTET1 overexpression, and enriched environment on adult hippocampal neurogenesis. a. Representative images of BrdU immunofluorescence in the DG and quantification of BrdU+ cells. b. Representative images of DCX/BrdU immunofluorescence in the DG. Quantification of DCX+ cells, BrdU+ cells, and DCX+/BrdU+ cells. c. Representative images of NeuN/BrdU immunofluorescence in the DG. Quantification of NeuN+ cells, BrdU+ cells, and NeuN+/BrdU+ cells. Data are expressed as the mean \pm SEM, $n=3-4$ per group. Scale bar: $50 \mu m$. * $p<0.05,{ }^{*} p<0.01$. Abbreviations: $2 \mathrm{VO}$, bilateral common carotid artery occlusion; AAV, adeno-associated viral; hTET1, human Ten-eleven translocation methylcytosine dioxygenase 1; EE, enriched environment 
Fig.4

a

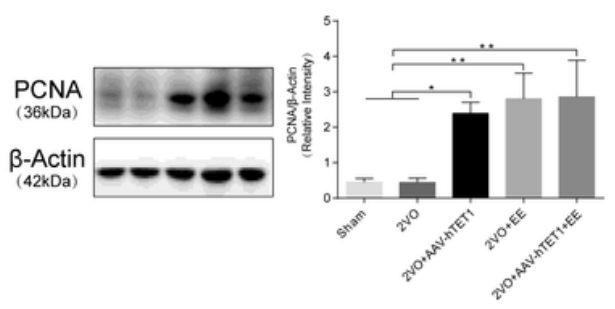

C
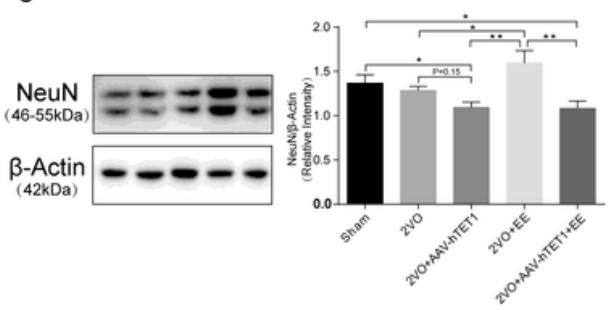

e
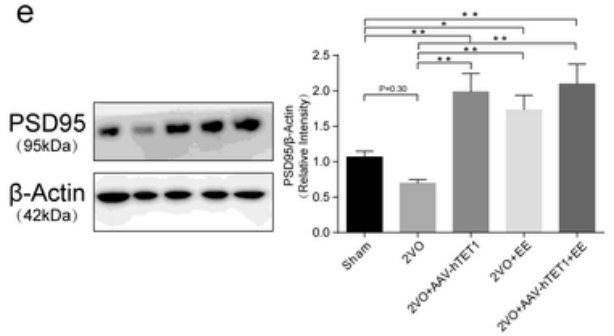

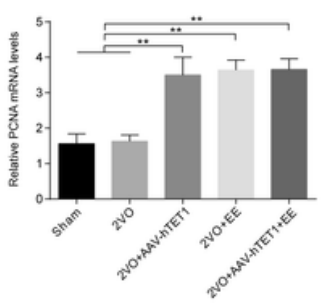

b
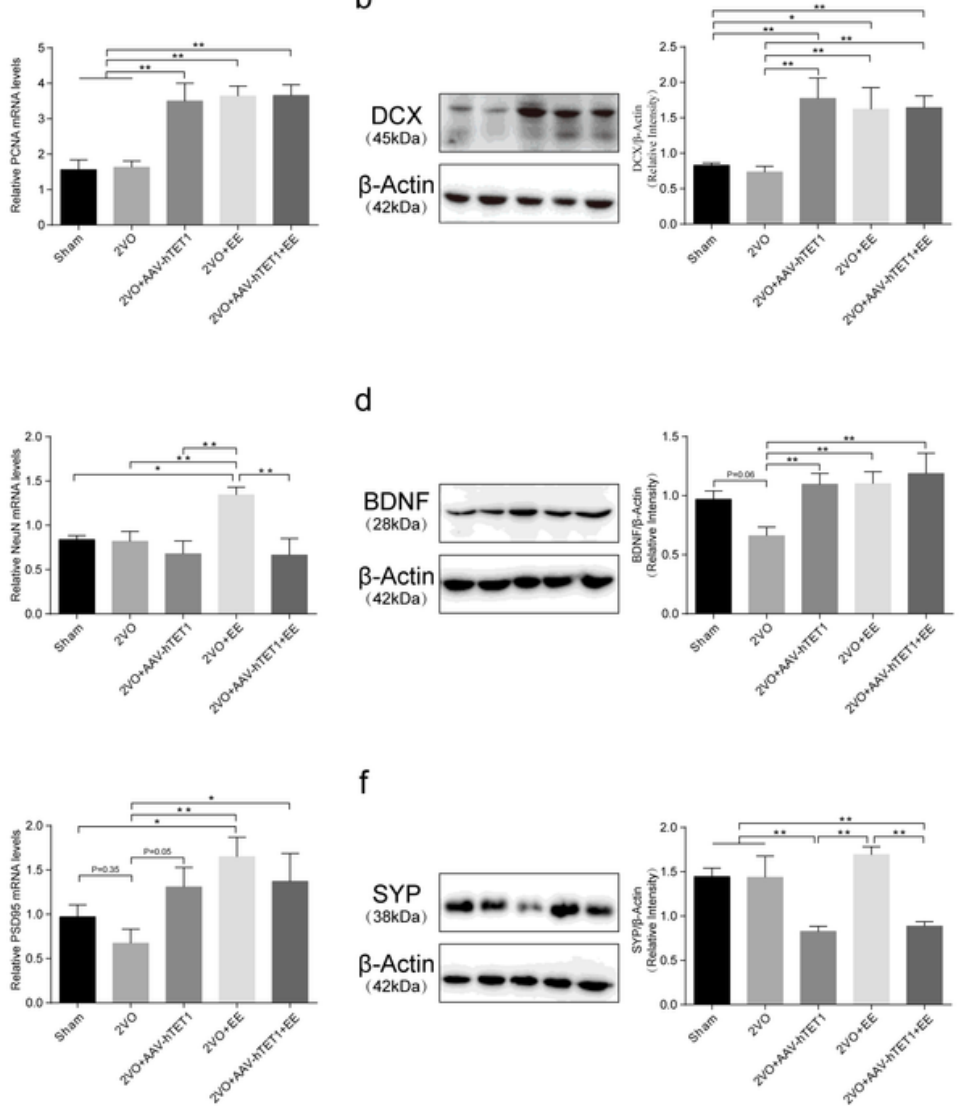

$\mathrm{d}$

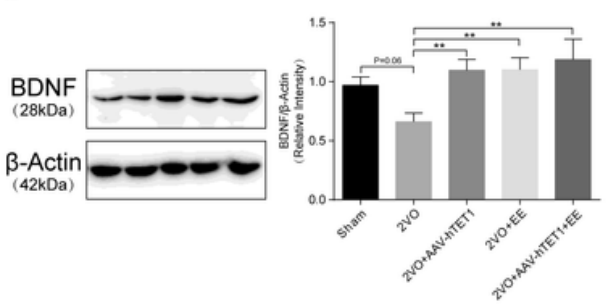

f

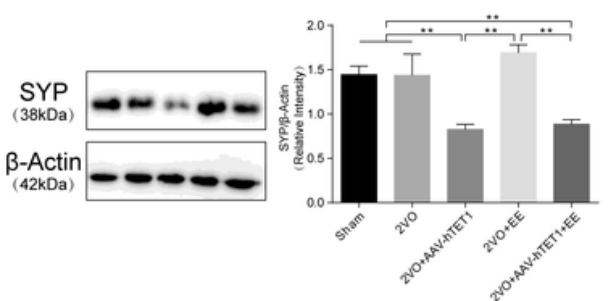

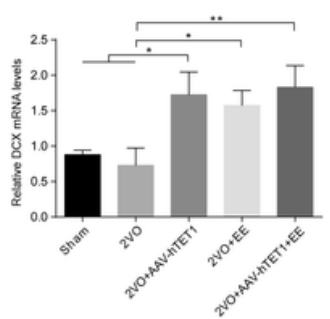
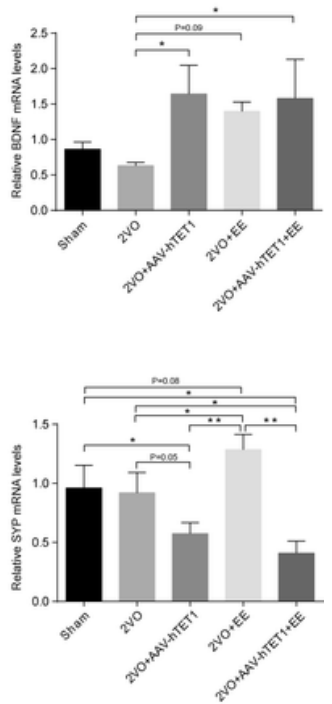

Figure 4

Effect of chronic cerebral hypoperfusion, hTET1 overexpression, and enriched environment on adult hippocampal neurogenesis markers. Representative western blot images of PCNA, DCX, NeuN, BDNF, PSD95 and SYP. Quantification of the relative optical densities of hippocampal PCNA, DCX, NeuN, BDNF, PSD 95 and SYP ( $n=6-8)$. Quantification of the mRNA expression level of PCNA, DCX, NeuN, BDNF, PSD95 and SYP ( $n=5-6)$. All results are expressed as the mean \pm SEM. ${ }^{*} p<0.05,{ }^{* *} p<0.01$. Abbreviations: 2 VO, bilateral common carotid artery occlusion; AAV, adeno-associated viral; hTET1, human Ten-eleven translocation methylcytosine dioxygenase 1 ; EE, enriched environment 
Fig.5
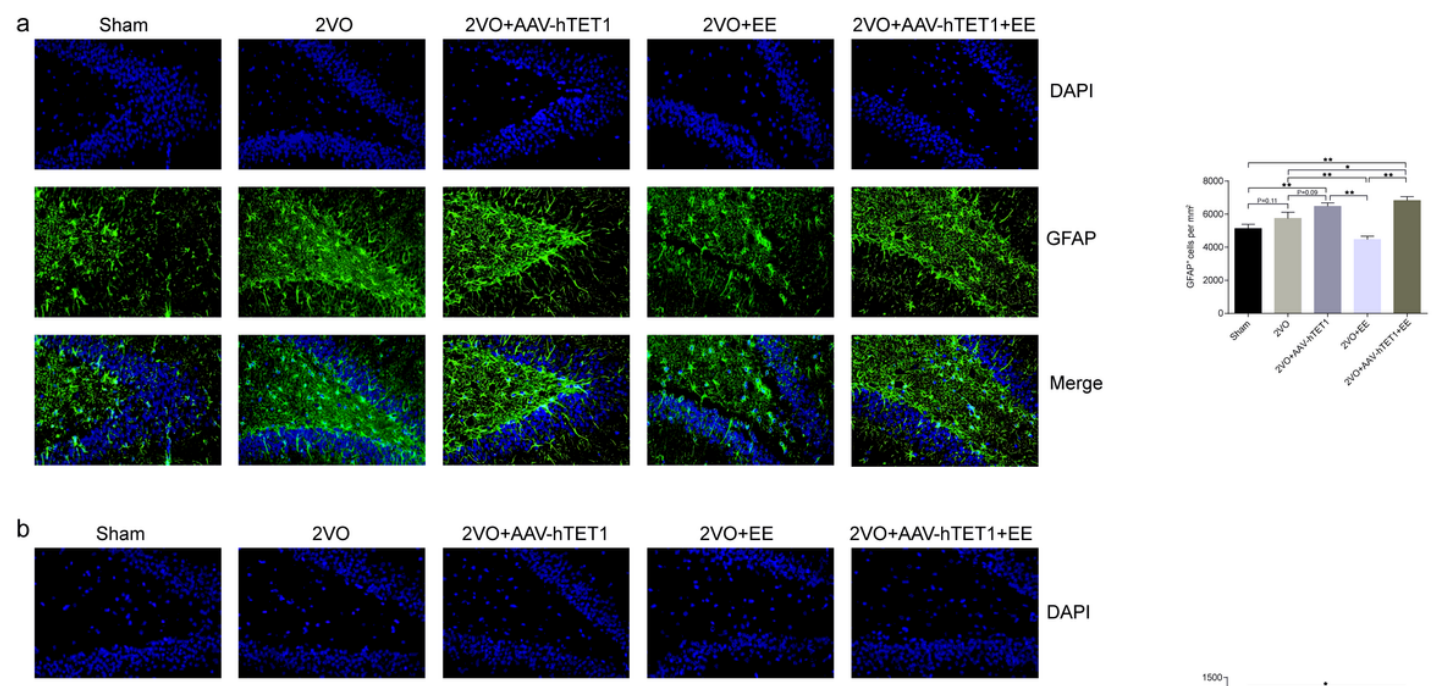

2VO+AAV-hTET1+EE
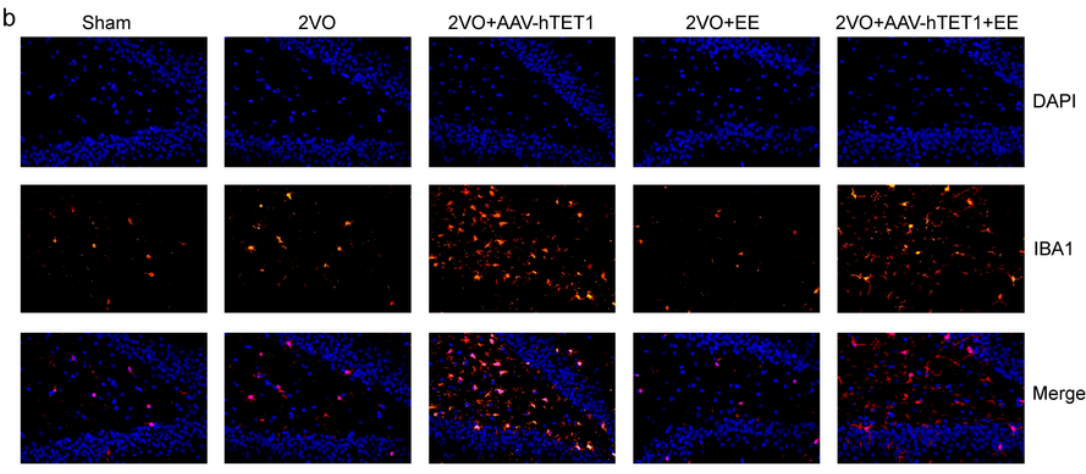

d
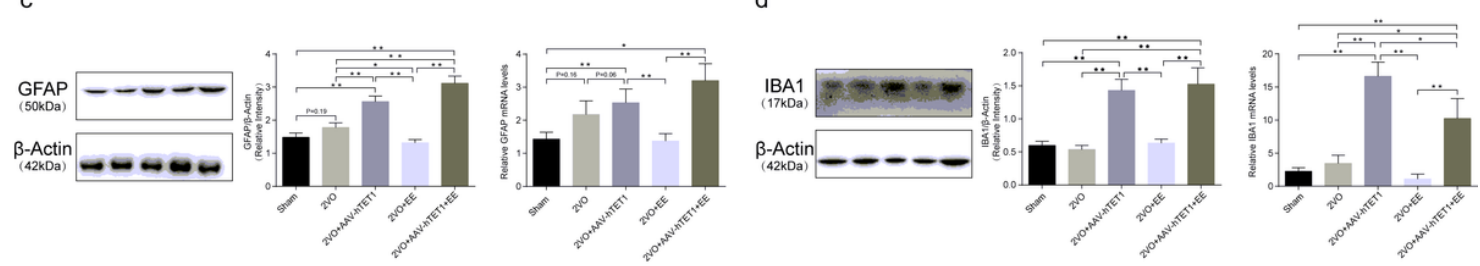

Figure 5

Effect of chronic cerebral hypoperfusion, hTET1 overexpression, and enriched environment on glial reactivity. a. Representative images of GFAP immunofluorescence in the DG. Quantification of GFAP+ cells $(n=3-4)$. b. Representative images of IBA1 immunofluorescence in the DG. Quantification of IBA1+ cells ( $n=3-4)$. c-d. Representative western blot images of GFAP and IBA1. Quantification of the relative optical densities of hippocampal GFAP and IBA1 $(n=6-8)$. Quantification of the mRNA expression level of GFAP and IBA1 $(n=5-6)$. Data are expressed as the mean \pm SEM. Scale bar: $50 \mu m$. ${ }^{*} p<0.05,{ }^{*} p<$ 0.01 . Abbreviations: $2 \mathrm{VO}$, bilateral common carotid artery occlusion; AAV, adeno-associated viral; hTET1, human Ten-eleven translocation methylcytosine dioxygenase $1 ; E E$, enriched environment 
Fig.6
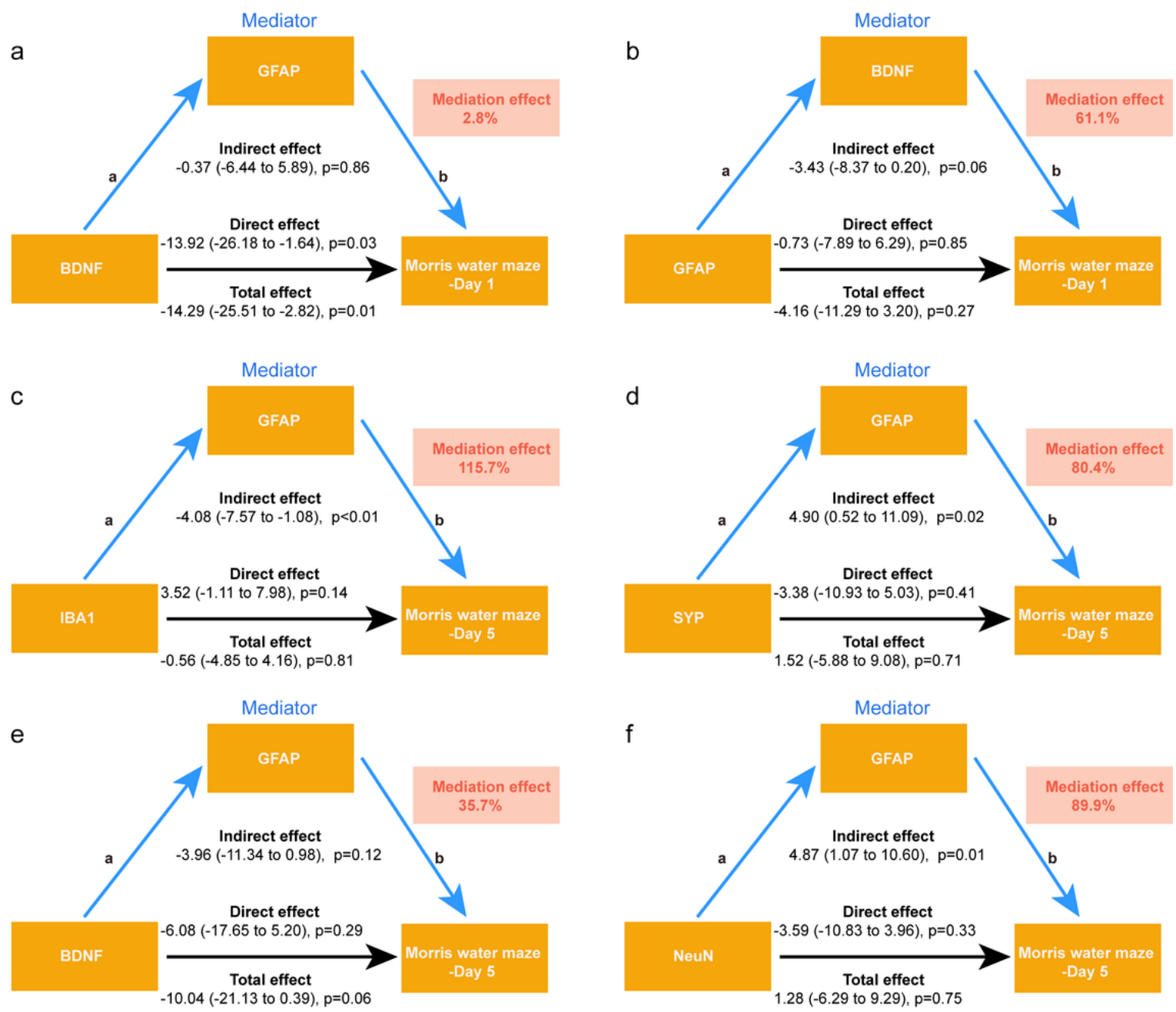

\section{Figure 6}

Causal mediation analysis for neuronal, synaptic and glial markers on cognitive function. Diagrams present the standardized regression coefficients controlling for confounders associated with each path in the model. The bootstrap statistical significance ( $p$ values) of the direct and indirect paths is presented in each diagram. The mediation effect is the indirect effect expressed as a percentage of the total effect. 
Fig.7

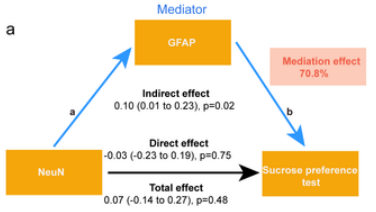

c

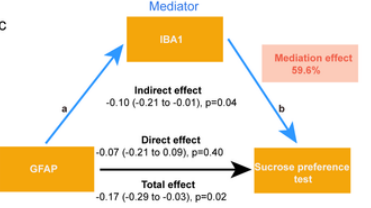

e

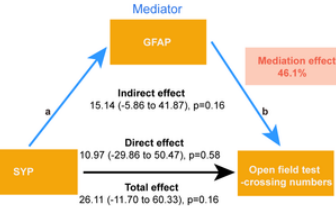

g
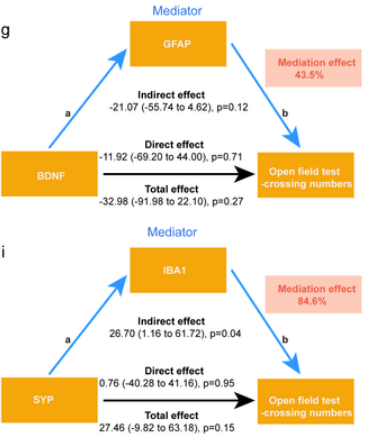

$\mathrm{k}$

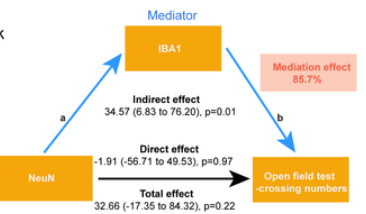

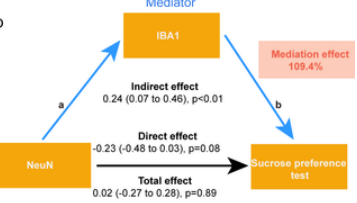
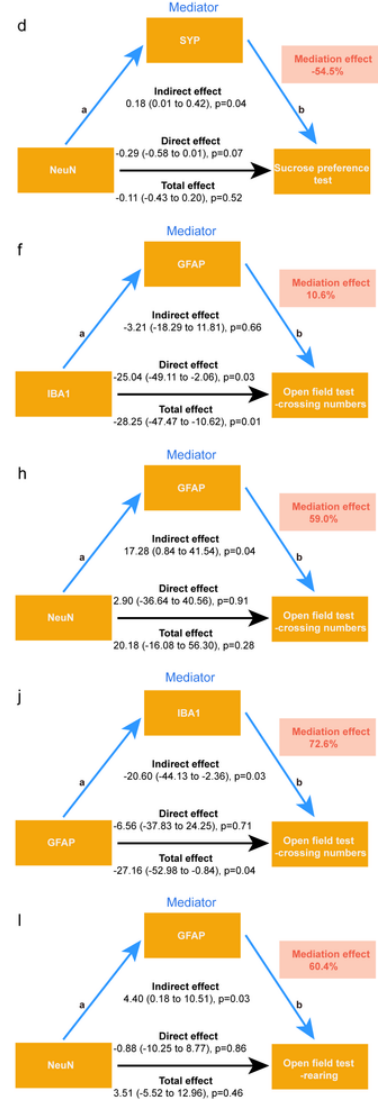

Figure 7

Causal mediation analysis for neuronal, synaptic and glial markers on depressive-like behaviors. Diagrams present the standardized regression coefficients controlling for confounders associated with each path in the model. The bootstrap statistical significance ( $p$ values) of the direct and indirect paths is presented in each diagram. The mediation effect is the indirect effect expressed as a percentage of the total effect. 


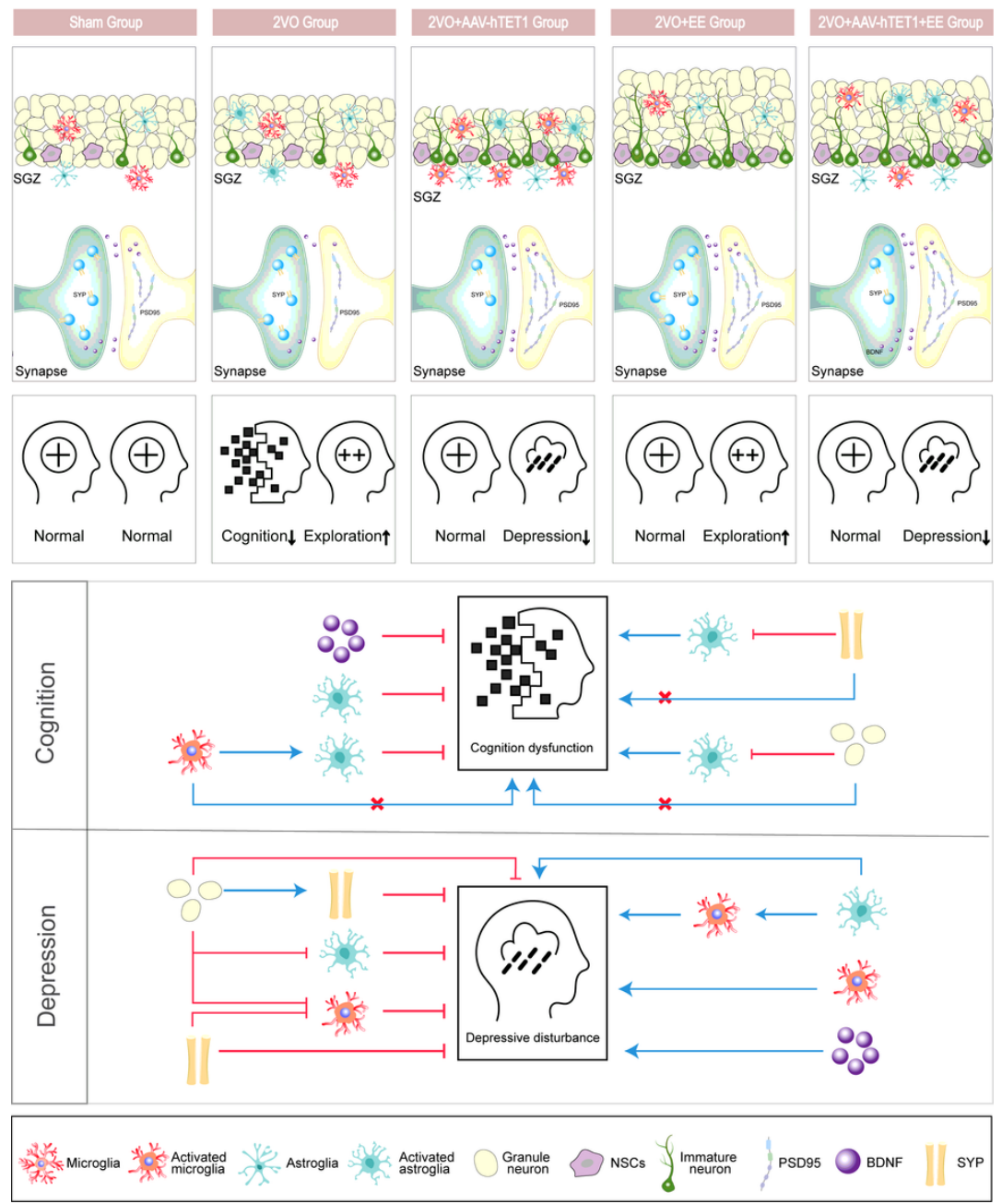

Figure 8

Brief mechanistic summary of chronic cerebral hypoperfusion, hTET1 overexpression, and enriched environment. Chronic cerebral hypoperfusion led to spatial memory dysfunction and hyperactive of autonomous exploratory ability. Regrettably, chronic cerebral hypoperfusion made little effect on adult neurogenesis, microglia and astrocyte reactivity, synaptogenesis and neurotrophic factor changes. Both AAV-hTET1 administration and enriched environment ameliorated the hypoperfusion-induced cognitive dysfunction via improved adult hippocampal neurogenesis and accompanied synaptogenesis and neurotrophic factor. However, genetical treatment or enhanced environment might emerge diverse mechanistic insights to make a completely contrary effect on psychiatric disturbances and glial activation might be devoted to this discrepancy. AAV-hTET1 administration might deteriorate depression by elevated glial reactivity, but enhanced environment might ameliorate the depression by decreased glial activation. Stimulating ANH through genetical treatment or EE was not sufficient for ameliorating the cognitive dysfunction and depressive-like behaviors. Healthy local brain environment with elevated BDNF and less astroglial reaction was conducive to improve cognitive dysfunction. Furthermore, depressive disturbances were determined by astroglial and microglial activation, as well as neuronal and presynaptic function.

\section{Supplementary Files}

This is a list of supplementary files associated with this preprint. Click to download.

- 5AnnotationoffiguresS.docx

- Figs1.tif

- Figs2.tif

- FigS3.tif

- Figs4.tif

- Figs5.tif

- Figs6.tif

- FigS7.tif

- FigS8.tif 
- FigS9.tif

- TableS1PrimersequencesusedforRTPCR.docx

- TableS2AntibodiesforWBandIF.docx

Page 20/20 